OPEN ACCESS

Edited by:

Roland Michael Tisch,

University of North Carolina at

Chapel Hill, United States

Reviewed by:

Theresa $L$ Whiteside,

University of Pittsburgh, United States

Valerie Lebleu,

University of Texas MD Anderson

Cancer Center, United States

*Correspondence:

Fausto Almeida

fbralmeida@usp.br

Specialty section:

This article was submitted to Immunological Tolerance and Regulation,

a section of the journal

Frontiers in Immunology

Received: 18 May 2021

Accepted: 30 June 2021

Published: 14 July 2021

Citation:

Santos P and Almeida F (2021) Exosome-Based Vaccines: History, Current State, and Clinical Trials.

Front. Immunol. 12:711565. doi: 10.3389/fimmu.2021.711565

\section{Exosome-Based Vaccines: History, Current State, and Clinical Trials}

\author{
Patrick Santos and Fausto Almeida * \\ Department of Biochemistry and Immunology, Ribeirão Preto Medical School, University of São Paulo, Ribeirão Preto, Brazil
}

Extracellular vesicles (EVs) are released by most cell types as part of an intracellular communication system in crucial processes such as inflammation, cell proliferation, and immune response. However, EVs have also been implicated in the pathogenesis of several diseases, such as cancer and numerous infectious diseases. An important feature of EVs is their ability to deliver a wide range of molecules to nearby targets or over long distances, which allows the mediation of different biological functions. This delivery mechanism can be utilized for the development of therapeutic strategies, such as vaccination. Here, we have highlighted several studies from a historical perspective, with respect to current investigations on EV-based vaccines. For example, vaccines based on exosomes derived from dendritic cells proved to be simpler in terms of management and cost-effectiveness than dendritic cell vaccines. Recent evidence suggests that EVs derived from cancer cells can be leveraged for therapeutics to induce strong anti-tumor immune responses. Moreover, EV-based vaccines have shown exciting and promising results against different types of infectious diseases. We have also summarized the results obtained from completed clinical trials conducted on the usage of exosome-based vaccines in the treatment of cancer, and more recently, coronavirus disease.

Keywords: extracellular vesicles (EV), immunization, infectious diseases, cancer, exosomes

\section{EXOSOME FUNCTIONS: BIOGENESIS AND CARGO}

Extracellular vesicles (EVs) are a group of biological, nano-sized, bilayered membrane vesicles produced by almost all cells. EVs can be found naturally in body fluids, such as blood, saliva, and breast milk (1-4). Classically, EVs are classified by size, molecular cargo, and the biogenesis pathway (5). However, there was a debate in literature regarding the definition of EVs due to inconsistencies in EV purification and characterization $(6,7)$. Fortunately, significant progress has been achieved regarding the establishment of criteria for a standardized nomenclature of EVs, and minimal requirements are set for experimental controls during EV separation, concentration and, characterization endorsed by the International Society of Extracellular Vesicles (ISEV) (8). In terms of biogenesis, EVs can be broadly divided into two dominant classes, namely exosomes and microvesicles (MVs). Exosomes are $30-150 \mathrm{~nm}$ EVs that initially demonstrate formation as intraluminal vesicles inside multivesicular bodies (MVBs) and are released after fusion of MVBs 
with the plasma membrane $(3,6,9,10)$. Microvesicles are formed by the outward budding of the plasma membrane, a process regulated by the translocation of phospholipids $(9,11)$. However, according to ISEV, there is no consensus on specific markers of each EV subtype, therefore assigning an EV to a specific biogenesis remains a challenging process (8).

In the extracellular space, exosomes can undergo fusion with the plasma membrane of recipient cells and deliver their packaged cargo into the cytosol. Exosomes are highly heterogeneous vehicles that can transport a wide variety of molecules, including lipids, proteins, and nucleic acids, such as mRNAs and miRNAs. The transport of these molecules can occur within the exosome itself or via attachment with the surface of recipient molecules, as evidenced in the case of major histocompatibility complex (MHC) molecules (12). Healthy cells release exosomes under normal physiological conditions that play a role in several cellular processes, for example, intercellular communication by facilitating the carriage and delivery of multiple molecules that can modulate crucial processes, such as growth, differentiation, and stress response $(13,14)$. Thus, considerable research attention is focused on the biology of EVs. However, according to Edgar (15), emerging interest in exosome biology is attributable to the association of exosomes with disease development. Indeed, infectious, inflammatory, and neurodegenerative diseases, as well as cancer, exhibit specific biomarkers that are carried by their respective exosomes (16-18).

\section{HISTORY OF EXOSOME-BASED VACCINES}

EV release was initially thought to be a random process; however, in 1983, two independent studies using different animal models discovered that reticulocytes released transferrin receptors inside EVs $(19,20)$. Barz et al. demonstrated that different lymphoma variants could produce EVs with distinct profiles of proteins and lipids that could be associated with tumor immune escape and cancer invasion (21). A year later, Schirrmacher and Barz observed that tumor-derived exosomes (TDEs) displayed antigens similar to their corresponding tumor cells (22). The same study was the first to show the anti-tumor effects of exosomes on cytotoxic lymphocytes (CTLs). In 1987, Johnstone et al. coined the term exosomes as a reference for EVs carrying transferrin receptors (23). Raposo et al. demonstrated the role of exosomes in antigen presentation by revealing MHC class II molecules in exosomes derived from B lymphocytes, which induced specific MHC class II $\mathrm{T}$ cell responses (24). These findings reveal that exosomes can be exploited as biomarkers and can be used in immunotherapeutic strategies for vaccine development.

The concept of a cancer vaccine is not new; it dates back to the early 70s. However, the feasibility of a vaccine against cancer is challenged by several issues, such as transplant rejection $(25,26)$. Tumor peptides have generated promising results and have shown potential applicability as a cancer therapeutic agent; however, peptide-based vaccines exhibit poor immunogenicity
(27-29). In 1998, Zitvogel et al. (30) published a study in which they found that DEXs (exosomes derived from dendritic cells) express functional MHC class I and II molecules. They observed that tumor peptide-pulsed dendritic cells (DCs) released DEXs presenting tumor antigens on the membrane, which induced in vivo CTL priming and consequent tumor growth suppression. This study was the first to support the development of a novel cell-free vaccine using exosomes, representing a milestone in exosome-based vaccine research.

In the new millennium, Wolfers and colleagues have reported that TDEs represent a source of T-cell cross-priming which is realized via transfer of antigens to DCs, and this induces CTL anti-tumor responses in vitro and in vivo (31). During in vitro stimulations, TDEs were more effective in eliciting protection against autologous tumors than other cancer immunization strategies, such as irradiated tumor cells, apoptotic bodies, or tumor lysates $(31,32)$. In 2004, the Zitvogel group published two articles that comprehensively described the transfer of MHC class I molecules from DEXs to naïve DCs for efficient CTL activation, and the role of toll-like receptors in combination with DEXs in triggering an MHC-restricted response in $\mathrm{CD}^{+} \mathrm{T}$ cells using in vitro stimulations and HLA-A2 transgenic mice $(33,34)$. In the same year, exosomes released by plasmacytoma cells were successfully used as a cancer vaccine; in this case, plasmacytoma exosomes conferred protection to the animals through reduction in tumor growth by $80 \%$ after a single vaccination (35). The use of exosome-based vaccines has since spread to different research areas outside cancer therapy. Exosomes derived from DCs previously co-cultivated with Toxoplasma gondii generated a strong and specific immune response to induced acute and chronic toxoplasmosis (36). Further investigation using Toxoplasma gondii has been detailed in section 5. Exosomes derived from an antigenic extract of Salmonella enteritidis strain were isolated and cultivated with serum samples obtained from naturally infected and healthy chickens (37). After completion of the exosome treatment, surface structures from Salmonella, such as flagellin and porins, were found to be immunogenic in serum samples collected from infected chickens but did not exhibit immunogenicity in healthy ones. These results represented a concrete evidence highlighting that Salmonella-derived exosomes could be used in the preparation of vaccines (37). Recently, a vaccine was designed by using a plasmid to generate Salmonella exosomes containing highly immunogenic membrane antigens and it showed satisfactory immune responses against several Salmonella strains (38).

From this point onward, exosome research increased due to the development of more sophisticated techniques, such as exosome engineering for drug delivery systems and artificial antigen presentation models (Figure 1). In the mid-2000s, the first results from clinical trials on exosome-based vaccines were reported (39-43). Clinical trials using exosome-based vaccines have been detailed in section 6. Currently, several exosome-based vaccine candidates are under development for diseases such as cancer, AIDS, hepatitis B, and other infectious diseases (44-48). The vaccines have been discussed in further detail in the subsequent sections. 


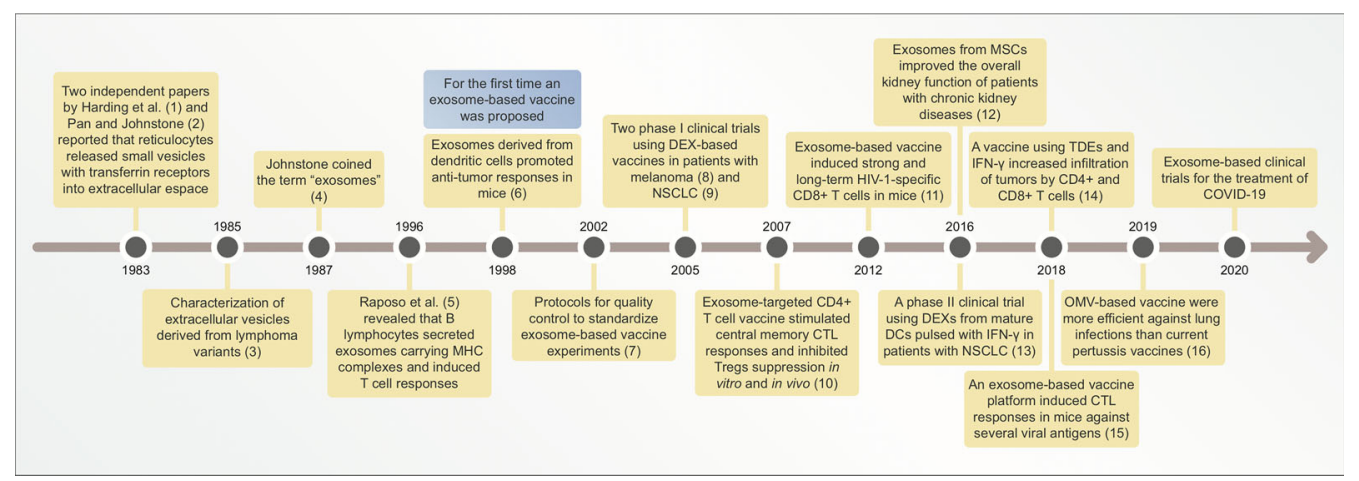

FIGURE 1 | Timeline illustrating main discoveries related to exosome-based vaccines. CTL, cytotoxic lymphocyte; DEXs, exosomes derived from dendritic cells (DCs); NSCLC, non-small cell lung cancer; MSCs, mesenchymal stem cells; TDEs, tumor-derived exosomes; OMV, outer membrane vesicle; COVID-19, coronavirus disease-19.

\section{EXOSOME-BASED VACCINES AS A CANCER THERAPEUTIC STRATEGY}

Tumor cells can evade immune surveillance through several regulatory mechanisms, such as reduced immune recognition or the establishment of an immunosuppressive tumor microenvironment (49). In this scenario, cancer cells can undergo proliferation and facilitate the recruitment of immune and stromal cells to favor tumor progression, which can lead to metastasis (50). Cancer immunotherapy has emerged as a clinical strategy for controlling the immune system and for reactivating anti-tumor immune responses (51). Immunotherapy approaches include targeting of immune tolerance via co-inhibitory checkpoints, adoptive T-cell therapy, and cancer vaccination (52).

Cancer vaccines differ from traditionally engineered vaccine for infectious diseases in the intervention approach. Traditional vaccines are preventive, on the other hand, cancer vaccines are focused on the therapeutic aspect. However, there are prophylactic interventions to reduce cancer incidence, morbidity, and mortality for virus-related cancers, such as hepatitis B (HBV) and human papilloma virus (HPV) (53). Therapeutic cancer vaccines can target a wide variety of antigens expressed by cancer cells, including antigens that are exclusively expressed in cancer cells, also known as tumorspecific antigens (TSAs), for example, mutated P53 and RAS. Cancer vaccines can also target antigens that have low levels in normal but highly expressed in tumor cells, the tumor-associated antigens (TAAs), such as MAGE-1, HER2, and HPV (54-56). There are also different platforms available, such as peptidebased, DNA-based, protein-based, viral-based, whole cancer cells, recombinant factors, and pulsed DCs $(53,56-58)$. Currently, only three cancer vaccines are approved for clinical use by FDA to treat early-stage bladder cancer (TheraCys ${ }^{\circledR}$ ), metastatic castration-resistant prostate cancer (PROVENGE), and metastatic melanoma $\left(\right.$ IMLYGIC $^{\circledR}$ ). These vaccines have produced slightly improved overall survival of patients with early-stage disease (58). For patients with advanced or metastatic tumors, cancer vaccines are likely to have a therapeutic role in a combination therapy approach (59).

Despite suboptimal results, recent cancer vaccine interventions are clinically promising and have shown potential applicability, especially with respect to overall patient survival (60). According to Melief et al., a robust cancer vaccine design must enable the induction of potent effector $\mathrm{CD}^{+}$and $\mathrm{CD} 8^{+} \mathrm{T}$-cell responses (60). Target antigen selection is challenging; selection is based on overexpressed antigens in tumors relative to normal tissue (61). Owing to the immunosuppressive tumor microenvironment, cancer vaccines should be administered in combination with adjuvants to overcome immunosuppression (62). Adjuvants are key components of several successful vaccines that boost the vaccine's immune response, quality, and efficacy (63). An interesting strategy for vaccines based on TAAs is the use of a combination of adjuvants and immunomodulatory antibodies (62). Exosomes exhibit features for application as adjuvant carriers, such as optimal size, biocompatibility, stability in systemic circulation, and target-specific delivery (64). Recently, an exosome-based adjuvant delivery system was developed using genetically modified murine melanoma B16BL6 cells, in which the exosomes derived from these cells containing CpG DNA were injected three times with a 3-days intervals and successfully induced immunostimulatory signals in mice 7 days after the last immunization (65). These results shed light on the novel use of exosomes as adjuvant carriers for future cancer vaccine development. Adjuvant strategies to increase cancer vaccine efficacy have been thoroughly reviewed by Bowen et al. (62).

To design a successful cancer vaccine, researchers must also consider administration routes and optimal delivery vehicles. DC injection is a common delivery system that triggers initiation and controls the direction of antigen-specific immune responses (64). However, DC-based immunotherapy has shown inconclusive results in clinical trials. Moreover, DC vaccines are an expensive therapeutic strategy for implementation in large populations, and they are difficult to ensure standardized production and lose efficacy over long periods of storage $(49,66)$. DEXs have emerged 
as a viable option for cancer vaccination because they possess higher stability for a longer period than DCs because of their lipid composition. DEXs also possess more peptide-MHC I and -MHC II complexes than DCs, thereby rendering the use of DEXs a less time- and space-consuming strategy (Figure 2A) (66-68). Additionally, DEXs are more resistant to immunosuppressive mechanisms in the tumor microenvironment than DCs (69). Exosomes are reportedly more capable of inducing immunocompetence in DCs than in microvesicles. An in vivo comparison of immunostimulatory potential between microvesicles and exosomes derived from ovalbumin (OVA)pulsed DCs showed that only exosomes induced antigen-specific $\mathrm{CD}^{+} \mathrm{T}$ cells and increased the proportion of germinal center $\mathrm{B}$ cells. Exosomes were also superior in terms of OVA levels, while microvesicle-associated OVA was barely detectable; however, microvesicles and exosomes both induced higher OVA-specific IgG production relative to controls (70).

Several studies revealed that DEXs can activate $\mathrm{CD} 4^{+}$and $\mathrm{CD}^{+} \mathrm{T}$ cells, indicating the ability of DEXs successfully carry antigen-MHCI/II complexes in vivo and in vitro (34, 71-73). Once activated, $\mathrm{CD}^{+} \mathrm{T}$ cells can become memory $\mathrm{T}$ cells. Wang et al. using a melanoma mice model, induced the $\mathrm{CD} 8^{+} \mathrm{T}$ cells differentiation to CTLs via DEXs from mature DCs. Three months after the immunization, the immunized mice group was boosted with DEXs and the number of CD8+ T cells expressing antigen-specific $\mathrm{T}$ cell receptor (TCR) was expanded six- to seven-fold in immunized mice. Another experiment in this study was to challenge immunized mice and control groups with melanoma cells three months after immunization protocol. Immunized mice were tumor free and control mice died of lung metastases. Moreover, these antigen- specific CD8+ T cells express CD44, a marker for memory T cells (74). The immunological memory induced by DEXs was also observed in CD4+ T cells of mice treated with OVA-pulsed DEXs, which induced an immune response towards to Th1 type. Interestingly, in this study, an efficient long term memory response of OVA-specific Th1 cells after a boost was dependent of prior B cell activation (75). $\mathrm{CD}^{+}$cells after uptake OVA-pulsed DEXs could stimulate efficient antigenspecific CTL responses and long-term $\mathrm{T} \mathrm{CD}^{+}$cell memory in immunized C57BL/6 mice against OVA-transfected melanoma cells expressing OVA challenge after three months of complete immunization (76). On the other hand, DEX vaccines failed to induce antigen-specific $\mathrm{T}$ cell responses in clinical trials (further discussed in section 6). Preclinical results showed that DEXs released by DCs treated with interferon- $\gamma($ IFN- $\gamma$ ) express high levels of molecules capable to induce a strong $\mathrm{CD}^{+} \mathrm{T}$ cell activation, such as CD40, CD80, CD86, and CD54 (77). However, this enhancing DC strategy did not translate into results in a phase II clinical trial, which the peptide-specific $\mathrm{T}$ cell responses were not detectable (43).

Recently, a combination of cancer vaccination and checkpoint blockade strategies was designed to induce antitumor responses in vitro and in vivo. Exosomes released by modified anti-CTLA-4 antibody and OVA-pulsed DCs

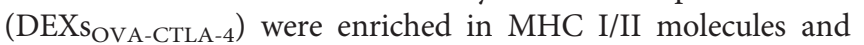
were found to exert strong T-cell activation and proliferation in vitro. Vaccination with DEXs $\mathrm{SVA-CTLA}_{\mathrm{O}}$ increased the migration of $\mathrm{CD}^{+}$and $\mathrm{CD}^{+} \mathrm{T}$ cells to the tumor site and elevated the ratio of CTLs/Tregs in the microenvironment of B16 melanoma tumor model after 12 days (78). Hao et al. demonstrated that exosomes derived from OVA-pulsed DCs and their uptake by

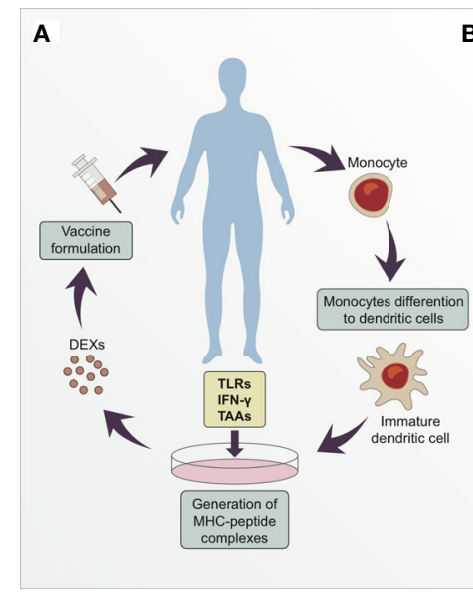

B

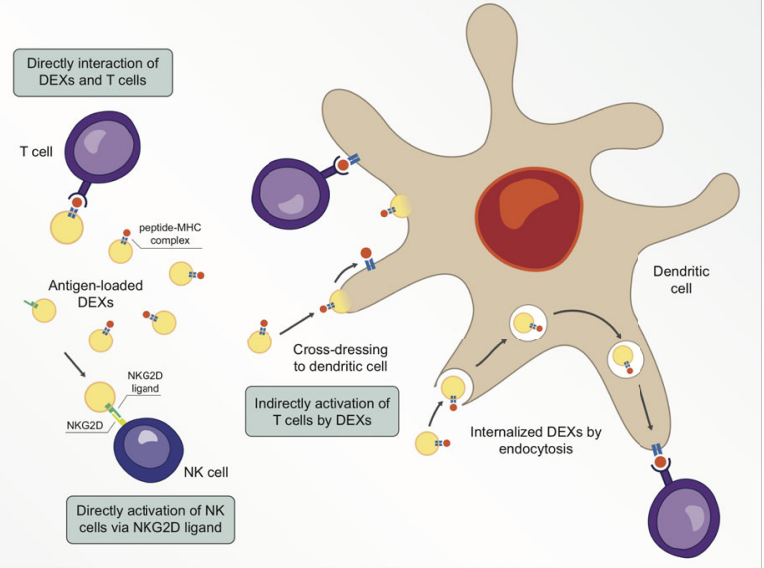

FIGURE 2 | Exosomes derived from dendritic cells (DEXs) are potential targets for cancer therapeutic strategy. (A) Simplified illustration of a personalized vaccine using DEXs. (B) DEXs can directly catalyze the transfer of peptide-MHC complexes from their membrane surface to T cell membrane surface (cross-dressing). Moreover, DEXs can stimulate T cell responses in an indirect manner via cross-dressing with dendritic cells or via exosome uptake and processing, following the peptide-MHC complex presentation to T cells. DEXs can also induce activation and proliferation of NK cells by establishing interaction of the NKG2D ligand on DEXs with NKG2D receptors on the NK cell membrane. 
CD4+ T cells stimulated the proliferation and differentiation of central memory CTLs and inhibited Treg suppression in vitro using BL6 melanoma cells. Also, in this study, C57BL/6 mice immunized with OVA-pulsed DEXs showed an elevated number of OVA-specific $\mathrm{CD}^{+} \mathrm{CD} 44^{+} \mathrm{T}$ cells three months after the immunization in comparison to control group (42). Long-term functional CTL memory was observed in animals injected with OVA-pulsed DCs and was then challenged with OVA-expressing B16 melanoma cells (79). Different mechanisms of antigen presentation by DEXs have been proposed (Figure 2B) (80, 81). Recipient DCs may establish interaction with antigen-loaded DEXs via the endosomal pathway, followed by the transfer of the peptide-MHC complex to the DC surface membrane for antigen presentation to $\mathrm{T}$ cells (82). Furthermore, a second indirect antigen presentation mechanism called cross-dressing occurs when an acceptor DC captures DEXs by facilitating the merging of membranes and retains the peptide-MHC complex on the DC surface without processing $(80,83)$. The direct interaction of DEXs with $\mathrm{T}$ cells seems to demonstrate poor efficiency in stimulating $\mathrm{T}$ cell responses, therefore DEXs have less T cell stimulation potential than their parent DCs $(66,84)$. Some authors suggest that exosomes are not able to interact directly with effector cells, thus prior capturing and processing the exosomes by DCs is a superior pathway of priming specific $\mathrm{T}$ cells via DEXs $(75,81,85,86)$. A study using the direct interaction of DEXs with T cells showed that DEXs from mature DCs are better at stimulating $\mathrm{T}$ cells than DEXs from immature DCs (87). Robbins and Morelli suggest that the low ability of exosomes to stimulate $\mathrm{T}$ cells in vitro is probably due to the small size and dispersion of exosomes caused by Brownian motion (88). These authors also suggest that $\mathrm{T}$ cell stimulation by exosomes can be enhanced when exosomes are immobilized and at high concentration (88).

Damage-associated molecular patterns (DAMPs) are signaling molecules released by dying cells that trigger immune cells to activate defensive mechanisms (89). For example, tumorderived DAMPs establish interaction with Toll-like receptors (TLRs), which directly lead to the activation of $\mathrm{T}$ cells and indirectly result in the induction of the release of inflammatory cytokines (90). Damo and colleagues developed different exosome vaccines derived from OVA and TLR ligand-pulsed bone marrow DCs (91). Their results showed that the TLR-3 ligand-DEXs vaccine (OVA + poly I:C) stimulated higher antigen-specific $\mathrm{CD}^{+} \mathrm{T}$-cell proliferation and effector functions and increased the population of $\mathrm{TNF}^{+} \mathrm{CD}^{+} \mathrm{T}$ cells in the lymph nodes of vaccinated mice with melanoma compared to other vaccine formulations 19 days after priming. Additionally, this group showed that purified DEXs successfully carried melanoma epitopes and induced potent anti-tumor immune responses, thereby slowing tumor progression. Recently, a DEX-based vaccine combined with microwave ablation was reported to inhibit tumor growth in hepatocellular carcinoma (HCC) mouse models compared to microwave ablation (a common therapy for HCC patients) alone, in this case, the tumor disappeared 10 days after microwave ablation in combination with DEX injection (92). Additionally, HCC features a high expression level of $\alpha$-fetoprotein (AFP), which has been used as an HCC antigen for monitoring and diagnosis (93). DEXs from AFP-enriched DCs generated strong antigen-specific immune responses in vitro tumor suppression after 26 days in HCC mice under a vaccination regimen of a weekly injection for three weeks (71).

In addition to carrying MHC complexes on their surface, DEXs carry proteins that can stimulate cells of the innate immune system. For example, a study showed that DEXs expressing BAT3 on the surface, which is a protein responsible for engaging natural killer (NK) cell activation, induced NK cellmediated cytokine release in vitro (94). DEXs induced a strong NK cell activation and stimulated the release of IFN- $\gamma$ in a dosedependent manner via TNF in mice (95). DEXs also express several other ligands on their surface that can mediate innate immune functions, such as TNF, FasL, and TRAIL (95). Moreover, the DEX membrane contains the activating receptor NKG2D ligand, which is responsible for the activation and proliferation of NK cells (96).

Although DCs have been pulsed with TLRs, biomarkers, and tumor antigens derived from lysates, TDE-pulsed DCs were reported to generate the most remarkable results as a potential anti-tumor vaccination. As mentioned earlier, TDEs provide a broad range of TAAs for antigen presentation. TDEs also transfer mRNAs and non-coding RNAs, such as miRNAs and long non-coding RNAs (lncRNAs) $(97,98)$. Recent data suggests that mRNAs packaged inside TDEs are responsible for stimulating the immune response by MHC I cross-presentation to DCs (99-101). For example, TDEs derived from CD40L/41BBL-expressing Mel526 melanoma cells induce potent DC activation in vitro (100). The interaction of $4-1 \mathrm{BBL}$ with its receptor $4-1 \mathrm{BB}$ results in the formation of a complex that induces CD8+ T cell activation and expansion (102). Interestingly, peptides derived from introns and exons of mRNAs derived from mouse melanoma cells act as tumor-associated peptides that can be delivered to DCs and result in the promotion of CD8+ T cell activation and proliferation (99). A recent study using sequencing technology showed that exosomes derived from plasma of 150 patient with cancer contained abundant levels of lncRNAs that could act as potential biomarkers for cancer diagnosis, specially 5 lncRNAs that can serve as HCC biomarkers diagnosis (103). Exploitation of lncRNAs derived from TDEs seems promising as a vaccination approach. For example, LINC02195 is an lncRNA capable of regulating MHC I molecules during antigen processing and presentation (104). Furthermore, a signature was identified as a prognostic predictor of laryngeal cancer using the lncRNAs of TDEs (105).

A vaccine designed using TDE-loaded DCs showed superior immune response induction compared to tumor lysate-loaded DCs as evidenced by results obtained in mouse myeloid leukemia and renal cell carcinoma models (106). Recently, the same effect was observed in lung cancer, in which TDE-pulsed DCs induced a reduction in the population of regulatory $\mathrm{T}$ cells (Tregs) in vitro, while they suppressed tumor growth and increased animal survivability in vivo (107). DCs pulsed with TDEs derived from different types of cancers (such as leukemia, renal carcinoma, 
glioblastoma, and pancreatic cancer) elicit anti-tumor immune responses (108-112). DC activation and maturation can be induced by the high-mobility group nucleosome-binding protein 1 (HMGN1), a well-known Th1-polarizing alarmin $(113,114)$. TDEs bound to the N-terminal portion of HMGN were found to induce persistent anti-tumor immunity in orthotopic HCC mice (115).

In most studies, TDEs derived from patient sera have been found to be biocompatible and exhibit low immunogenicity. However, it is relevant that TDEs play roles in all steps of cancer progression, including metastasis and they can be immunosuppressive in certain types of cancer (115-117). The immune-suppressive potential of TDEs has been reported to inhibit the effector activity of CD4+ and CD8+ T cells and NK cells (118). Recently was demonstrated that TDEs can carry the programmed death ligand (PD-L1), which is responsible for $\mathrm{T}$ cell exhaustion (119). Moreover, TDEs can block the differentiation of DCs, induce apoptosis, and diminish the overall $\mathrm{T}$ cell responses in different types of cancer (120-122). In addition, several studies show that TDEs have potential to suppress the effects of therapeutic agents $(123,124)$, for example, TDEs are associated to acquired chemoresistance (125).

TDEs may also exert a dual effect, improving DC vaccine efficiency in vitro, while favoring tumor progression in vivo (117). Immunomodulatory molecules combined with TDEs may induce enhanced anti-tumor immune responses. For example, a vaccine designed with TDEs released by mouse cancer cell lines subjected to treatment with IFN- $\gamma$ and interferon receptor factor-1 (IRF-1) was found to increase the number of infiltrated CD4+ and CD8+ T cells and reduce tumor size in $\mathrm{C} 57 \mathrm{BL} / 6 \mathrm{~J}$ female mice transfected with Hepa 1-6 hepatoma cells or MC-38 colon carcinoma cells after 21 days of the exosome injection (46). Additionally, in a recent study reported by Shi et al., a vaccine with exosomes derived from IFN$\gamma$-modified RM-1 prostate cancer cells under a vaccination regimen of 4 injections (on days $0,4,8$, and 12), decreased the number of Tregs and reduced the tumor metastatic rate in C57BL male mice with lung metastasis (126). These findings indicate that pulsing DCs with a wide variety of molecules can help produce exosomes capable of generating a robust antitumor immune response (Table 1). These methods represent promising and potentially individualized TDE- and DEX-based vaccine strategies for cancer immunization.

\section{EXOSOME-BASED VACCINES FOR TREATMENT OF VIRAL INFECTIOUS DISEASES}

Similar to cancer, exosomes act as a double-edged sword because of their ability to carry and deliver molecules to target cells in infectious diseases. Exosomes play a crucial role in the pathogenesis of infection, but also trigger immune responses to confer protection against pathogens (134). This effect can be observed in the context of viral infections, where exosomes derived from infected cells can deliver viral content to surrounding cells, but can also induce antiviral immune responses (135). The "Trojan exosome" hypothesis proposed by Gould et al., describes the evolutionary similarities of viruses and exosomes with regard to their biogenesis and transmission pathways, suggesting exosomes as a potential tool for

TABLE 1 | Different experimental models and design using exosomes to induce anti-tumor immune responses against several types of cancer.

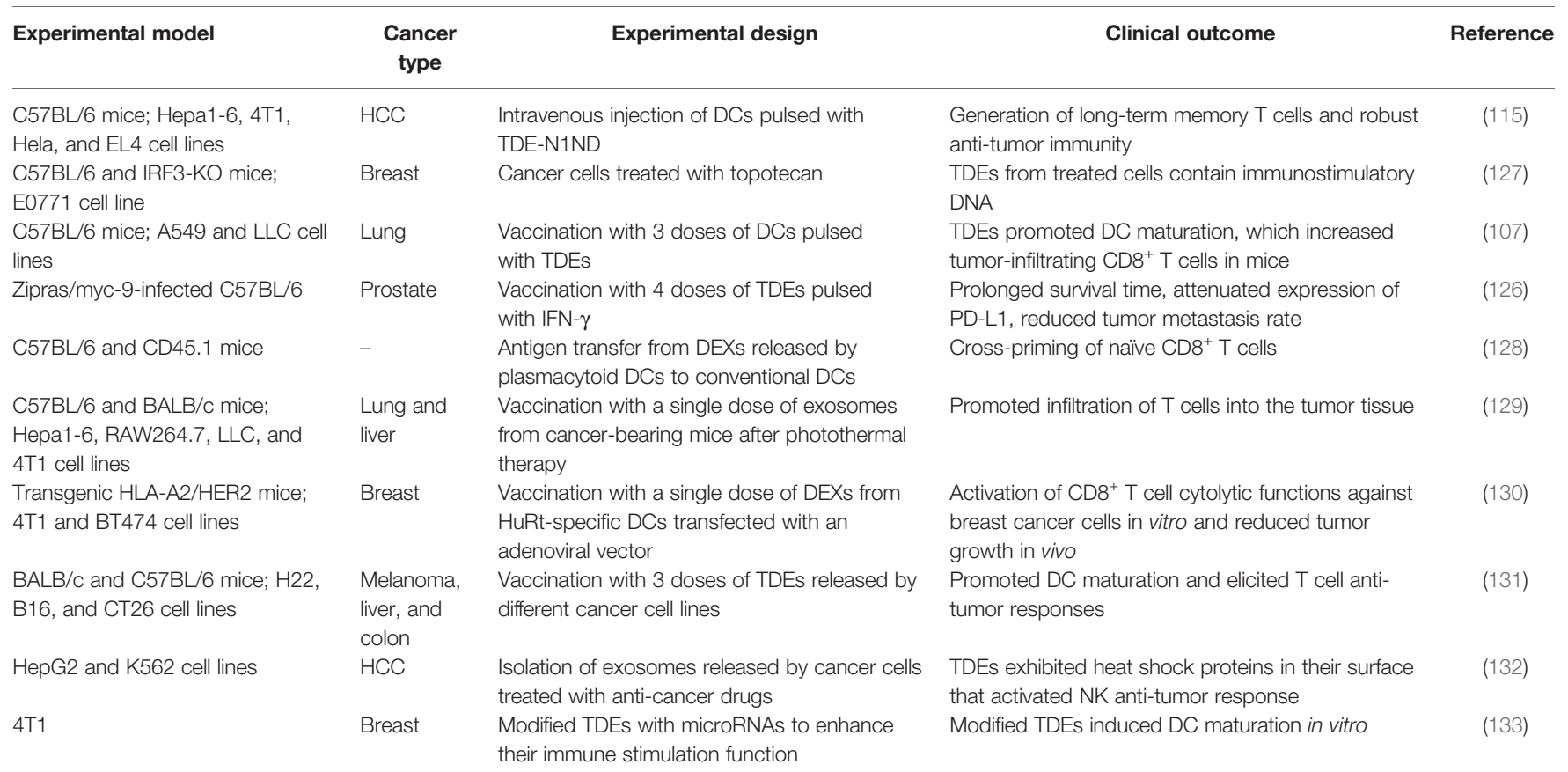


vaccination against human immunodeficiency virus (HIV) (136). The exosomal biogenesis pathway that is hijacked by HIV for viral spread can be exploited as a potential therapeutic approach (137).

Efforts are ongoing to evaluate the potential of exosome-based vaccines against HIV. Dr. Jim Xiang's research group pioneered this research area and developed a vaccine termed as Gp120Texo. This vaccine was designed with DEXs derived from DCs transfected with an adenoviral vector, $A d V_{G p 120}$, which expressed the HIV-specific envelope glycoprotein Gp120 (138). Gp120-Texo induced strong and long-term HIV-specific CD8 ${ }^{+}$ $\mathrm{T}$-cell responses independent of $\mathrm{CD} 4^{+} \mathrm{T}$ cells and DCs in mice $(44,138)$. Later, the Xiang group designed a vaccine to induce a specific immune response against Gag (Gag-Texo) (139), a group of proteins responsible for HIV maturation and infection (140). Gag-Texo induced Gag-specific immunity in animal models of chronic infection, suggesting that this vaccine might induce CTL responses to attack HIV-infected cells (139). Nef is an HIV protein associated with multiple cellular functions, such as the survival of infected cells and vesicular trafficking (141). An exosome-based vaccine was engineered by incorporating a Nef mutant $\left(\mathrm{Nef}^{\mathrm{mut}}\right)$ into exosomes. In this case, $\mathrm{Nef}^{\mathrm{mut}}$-exosomes were absorbed by DCs, which then presented the antigens, thereby eliciting CTL immune responses in mice against several viral antigens, such as those for HIV, Ebola, influenza, $\mathrm{HBV}$, and hepatitis C virus (HCV) $(47,142,143)$.

Even with current diagnostics and therapeutics that enable viral suppression, HBV continues to represent a major healthcare concern worldwide (144). HBV is frequently associated with the development of chronic liver diseases, such as HCC (145). Exosomes released by $\mathrm{HBV}$-infected cells contain several proteins encoded by the HBV genome, as well as miRNAs that regulate gene expression in host cells (146-148). This sheds light on the potential use of exosomes to understand HBV transmission and $\mathrm{HBV}$-host interactions. However, there is a lack of literature on exosome-based HBV vaccination. Few studies have investigated the potential of a general exosomebased vaccine platform for multiple viral antigens, including HBV. Additionally, a vaccine formulation designed with unmodified exosomes as adjuvants for the recombinant HBV antigen showed promising results, in which exosomes induced a Th1 immune response, thereby enhancing the levels of IFN- $\gamma$ in mice (149). These studies are in the early phase, and further investigations are warranted to identify therapeutic targets for consideration as vaccine candidates against HBV using exosomes as delivery systems or adjuvants.

Influenza virus infection is another example of a healthcare concern that causes significant morbidity and mortality worldwide (150). Despite the wide variety of vaccine types available for influenza infection, studies have shown that exosomes can be used as a new platform for designing influenza vaccines, with exhibition of advantages over classical vaccines $(151,152)$. For example, airway exosomes released during influenza virus infection can carry host proteins with anti-influenza properties and can help trigger immune responses (153). A study using LC-MS/MS showed that exosomes derived from infected cells also carried similar proteins as those reported in the influenza virions, representing an alternative pathway for the infection of new host cells (154). Lung and serum-derived exosomes from mice infected with influenza virus exhibit high levels of miR-483-3p, and this is associated with the induction of pro-inflammatory cytokine release $(155,156)$. According to the authors, further studies are warranted to determine whether the transfer of miR-483-3p is involved in the activation of innate immune responses or in the inflammatory pathogenesis of influenza virus infection. Another exosome-based vaccination approach to combat the influenza virus includes EVs released by gram-negative bacteria, which are referred to as outer membrane vesicles (OMVs) (157). Several recent studies have reported that $\mathrm{OMV}$-derived vaccines can induce strong immune protection against the influenza virus in vivo (158-161).

\section{EXOSOME-BASED IMMUNIZATION STRATEGY FOR NON-VIRAL INFECTIOUS DISEASES}

The release of exosomes by non-viral pathogens such as bacteria and parasites, plays an important role in pathogenesis by establishing interactions with the host immune system and by transferring resistance factors (162). However, exosomes and OMVs derived from bacteria have been reported to be potent immune modulators, rather than aiding pathogenesis (163). The potential of OMVs as immune activators has been investigated using models of different infectious diseases such as pertussis (whooping cough), which is caused by Bordetella pertussis, a gram-negative bacterium (164). Currently available vaccines aid the successful reduction of the morbidity and mortality caused by pertussis, but they are also associated with severe adverse effects and weak immune protection (165). According to the World Health Organization (WHO), there is no consensus regarding the antigenic composition of an optimal pertussis vaccine (https://www.who.int/biologicals/areas/vaccines/ apertussis/en/). Several studies have now shown that a B. pertussis OMV-based vaccine can overcome this composition issue, representing an attractive vaccination model for pertussis (166-168). A recent OMV-based vaccine conferred protection to mice against lung infection more effectively than the current commercial pertussis vaccines (48). Although overshadowed by gram-negative bacteria, EVs derived from gram-positive bacteria have also recently gained attention as a potential vaccine platform for several infectious diseases. EVs released by Staphylococcus aureus were modified to possess no toxicity and to serve as vaccine candidates. Genetically engineered EVs showed immunogenic effects and protected mice against lethal sepsis caused by S. aureus (169). Additionally, EVs derived from Streptococcus pneumoniae incubated with murine DCs were rapidly internalized and enhanced the release of tumor necrosis factor (TNF)- $\alpha$, which constitutes the inflammatory response (170). 
Investigations of exosome-based vaccines for infectious diseases are not limited to viruses and bacteria. Toxoplasmosis is a globally occurring infectious disease caused by the coccidian protozoan Toxoplasma gondii (171). Vaccines with live and attenuated tachyzoites are available for animals; however, these vaccines are not effective and safe for humans (172). Therefore, the development of a toxoplasmosis vaccine for humans is of considerable interest for public health. However, few studies have reported the effects of DEXs derived from DCs pulsed with T. gondii or Toxoplasma-specific antigens $(36,173)$. In a recent study, DEXs released by DCs stimulated with T. gondii lysate were inoculated intranasally and ocularly in mice, which subsequently triggered humoral and mucosal immune responses against Toxoplasma infection (174).

Schistosomiasis is a major parasitic disease caused by Schistosoma mansoni, affecting a myriad individuals and causing over 280,000 deaths annually worldwide (175). Thus far, there is no vaccine available for schistosomiasis, which underscores the need for the development of vaccines against this disease. Few authors have suggested the use of exosomes as a cell-free vaccination platform against S. mansoni infection (176178). Exosomes released by S. mansoni adult worms contain miRNAs and proteins involved in host-parasite interactions, such as invasion, nutrient acquisition, and immunomodulation (178). A study showed that S. mansoni-derived exosomes harbored several potential vaccine candidates, including proteins involved in multiple life cycle stages, underlining their potential utility in different stages of the parasite's life cycle (176). These findings represent a promising avenue for further investigation of the potential applicability of exosomes in the development of vaccines against infectious diseases.

\section{CLINICAL TRIALS USING EXOSOME-BASED VACCINES}

Clinical trials using exosomes can be divided into three categories with different approaches. First, exosomes can be used as carriers to deliver drugs to specific targets. Second, exosomes derived from mesenchymal stem cells. And last, incorporating specific mRNAs and miRNAs into exosomes elicit responses in patients (179). In 2005, results from two phase I clinical trials using DEX vaccines were obtained. The first trial reported the use of DEXs loaded with HLA-restricted melanoma-associated antigen (MAGE) peptides, which were infused into patients with HLA A2+ non-small cell lung cancer (NSCLC) (41). After the administration of four weekly doses, the vaccine was well tolerated by all patients. However, only onethird of the patients presented with MAGE-specific T-cell responses, while two of the four analyzed patients showed an increase in NK cell activity (41). The second trial reported the use of DEXs derived from DCs pulsed with MAGE and inoculated them to conduct immunization of melanoma patients. No major toxicity event was reported by any patient, except for the occurrence of a grade I fever (five patients out of fifteen); however, no MAGE-specific response of $\mathrm{CD}^{+}$and $\mathrm{CD}^{+}$cells was observed in peripheral blood. Interestingly, NK cell effector functions were also induced by the DEX vaccine, where eight of the thirteen patients presented with an increased number of NK cells infiltrating the tumor site (40).

According to $\mathrm{Fu}$ and colleagues, the lack of an immune response to these vaccines can be associated with the DC type selected by researchers in these clinical trials (69). They used immature DCs, while other studies showed that exosomes derived from mature DCs induced more potent T-cell priming. A phase II clinical trial reported the use of DEXs derived from mature DCs pulsed with IFN- $\gamma$ in patients with NSCLC, and no toxicity was observed, except for the occurrence of grade III hepatotoxicity in one patient. In this case, the DEX vaccine did not induce a cancer-specific $\mathrm{T}$-cell immune response but resulted in the induction of NK cell functions (43). According to the authors, IFN- $\gamma$ may lead to an upregulated expression of PD-1 ligands on DEXs, a well-known immune checkpoint that suppresses T-cell activity. Although these vaccines were designed to activate specific MHC-restricted T-cell responses, DEXs proved to be effective in activating NK cells in an MHCindependent manner. Interestingly, DEX-based vaccines have focused on direct CTL activation as an independent process in other immune cells. However, Näslund et al. showed that CD4 ${ }^{+}$ T cells and B cells were necessary for the DEX activation of CTL anti-tumor response (85).

Recently, a non-randomized phase I/II clinical trial showed promising results with a vaccine designed using exosomes derived from DCs pulsed with SART1, a biomarker of squamous cell carcinoma of the esophagus. Pulsed DCs obtained from patients could generate exosomes that were well tolerated and induced antigen-specific CTLs in seven patients (180). One patient of this study remained stable for 20 months after DEXs therapy, although he developed lung metastasis after the stable period. The other six patients had progressive disease and died in a period up to 10 months after vaccination. These findings indicate that the development of a personalized exosome-based immunotherapy is feasible, although incredibly challenging. Patient indication criteria and the preparation of highly competent DCs for vaccine formulation are keystones of a successful exosome-based treatment (180). According to $\mathrm{Xu}$ and colleagues, it is important to investigate the anti-tumor immunity induced by DEXs-based vaccines to confirm whether DEXs can be used as tumor antigens for an exosome-based vaccine (52).

In addition to DEX vaccines, other clinical trials using different exosome-based vaccines have been reported. One phase I clinical trial reported the use of exosomes derived from ascites (AEXs) in combination with granulocyte-macrophage colony-stimulating factor (GM-CSF) as immunotherapy for colorectal cancer. Injection of AEXs for colorectal cancer was safe and well tolerated by all patients during the four weekly doses administered. Patients with advanced colorectal cancer subjected to treatment with AEXs plus GM-CSF demonstrated a strong anti-tumor cytotoxic T-lymphocyte response against the carcinoembryonic antigen (181), a colorectal cancer biomarker 
(182). Exosome-based vaccines have also been developed for the treatment of chronic diseases other than cancer. A phase II/III clinical trial was conducted using exosomes derived from umbilical cord MSCs in patients with chronic kidney diseases, such as type 1 diabetes and interstitial nephritis (45). The participants in the study reported no significant adverse effects during or after the treatment. The use of exosomes derived from MSCs improved overall kidney function and inflammatory immune activity. Currently, tests involving the safety and tolerance of aerosol inhalation of exosomes derived from MSCs are part of a clinical trial comprising healthy volunteers (NCT04313647). Another clinical trial involving he investigation of the use of exosomes derived from MSCs as a therapeutic strategy is underway against macular holes (NCT03437759).

\section{Clinical Trials Using Exosomes as a Potential Vaccine Against Coronavirus Disease (COVID-19)}

More recently, due to the coronavirus pandemic, clinical trials for exosome-based therapy have shifted from cancer to COVID19 treatment for future vaccine development (183). To this date, there are in total, 12 active clinical trials using exosome interventions at ClinicalTrials.gov. A phase I (NCT04747574) and a phase II (NCT04902183) independent clinical trials are recruiting patients with moderate or severe COVID-19 infection to evaluate the safety and efficacy of exosomes overexpressing CD24 of two doses with a patient follow-up for 23 days. CD24 is a costimulatory molecule expressed on several hematopoietic cells, especially progenitor cells, such as B cell progenitors (184). However, CD24 is also associated with autoimmune diseases $(185,186)$. Two phase I and II clinical trials are being conducted to investigate the safety and efficiency within 28 days after the first treatment of aerosol inhalation of bone marrow MSCderived exosomes in severe patients hospitalized with SARSCoV-2 pneumonia and COVID-19 (NCT04602442 and NCT04276987). And another phase I/II clinical trial (NCT04798716) is investigating the safety and efficiency of an intravenous infection of MSC-derived exosomes every other day on an escalating dose of 2:4:8 in the treatment of severe patients with COVID-19. According to these clinical trials description, MSC-derived exosomes may reduce lung inflammation and pathological impairment. Thus far, only one trial has reported results (NCT04491240), and no adverse events have been reported in patients after inhalation of $3 \mathrm{ml}$ of MSC-derived exosomes twice a day for 10 days. However, there is no information about the source of MSCs used to generate exosomes and other relevant information concerning the aerosol formulation in this clinical trial. Additionally, another ongoing phase I/II clinical trial (NCT04389385) is investigating the safety and efficiency of inhaled exosomes derived from COVID-19 specific $\mathrm{T}$ cells that were activated and expanded in vitro via viral peptide exposure.

However, to this date, the clinical trials do not offer much information concerning the usage of exosomes to induce immunogenic properties and/or long-term memory response.
The actual scenario of clinical trials using exosomes against COVID-19 is still evaluating safety and efficacy of exosome treatments. When completed, the ongoing clinical trials can provide the foundation for the conduction of future studies using MSC-derived exosomes in healthy patients. With their ability to elicit anti-inflammatory effects and modulate immune responses (187), MSC-derived exosomes may be important for the future design and development of COVID-19 vaccines.

Recently, a statement published by the ISEV and the International Society for Cell and Gene Therapy (ISCT) encouraged the conduction of further research and clinical trials using exosomes as a therapeutic strategy against COVID-19 (188). However, this statement also underscores the need for good clinical practice and rational clinical trial design.

\section{CONCLUSION}

Initially, EVs were considered to demonstrate the sole function of cellular waste elimination; however, EVs are now recognized as crucial mediators of intercellular communication because of their capacity to deliver different molecules and transfer signals over long distances to modulate several physiological mechanisms. The immunomodulatory properties of EVs provide insights into their use as a cell-free therapeutic strategy for different diseases. Several studies have reported promising results on EV-based vaccines against different types of diseases, including cancer and numerous infectious diseases. However, exosomes from cancer cells modulate many aspects of intercellular communication, which they can play a crucial role in tumor progression and suppress anti-tumor activities. Understanding the dual effects of exosomes represent a major challenge for future therapies using exosome-based vaccines. Clinical trials showed modest results, with no antigen-specific response induced by exosome vaccines, i.e., MHC I/II-restricted TAAs did not stimulated anti-tumor properties in effector $\mathrm{T}$ cells. Further studies are needed to understand the pharmacokinetic of exosome-based vaccines. On the other hand, clinical trials revealed the ability of exosome-based vaccines in recruitment and activation of innate immunity. Further investigation is warranted for the development of new techniques for loading EVs with specific antigens or drugs, and for engineering EVs to display more efficiency in cargo delivery. When in combination with other therapies, exosome-based vaccines are more promising, for example, different studies showed that PD1/PDL1 blocking therapy combined with DEXs resulted in effective $\mathrm{T}$ cell activation (189). However, difficulties such as lack of quality control and standards for EV characterization and purification must be overcome. Also, logistical issues, such as manufacturing, storage, and administration of exosome-based vaccines need to be addressed (190). Additionally, exosome-based vaccination encompasses various issues on exosome biocompatibility for broad clinical usage and for the establishment of large-scale immunization programs. There are several challenges, including the development of an effective cell-free vaccine platform to use exosomes for the treatment of various diseases. A focus on such 
aspects and challenges is necessary for future exosome-based vaccine investigations.

\section{AUTHOR CONTRIBUTIONS}

FA conceived the idea. PS and FA designed, wrote, and edited the manuscript. All authors contributed to the article and approved the submitted version.

\section{REFERENCES}

1. Vlassov AV, Magdaleno S, Setterquist R, Conrad R. Exosomes: Current Knowledge of Their Composition, Biological Functions, and Diagnostic and Therapeutic Potentials. Biochim Biophys Acta (2012) 1820(7):940-8. doi: 10.1016/j.bbagen.2012.03.017

2. Wang X. Isolation of Extracellular Vesicles From Breast Milk. Methods Mol Biol (2017) 1660:351-3. doi: 10.1007/978-1-4939-7253-1_28

3. Colombo M, Raposo G, Thery C. Biogenesis, Secretion, and Intercellular Interactions of Exosomes and Other Extracellular Vesicles. Annu Rev Cell Dev Biol (2014) 30:255-89. doi: 10.1146/annurev-cellbio-101512-122326

4. Yu Y, Gool E, Berckmans RJ, Coumans FAW, Barendrecht AD, Maas C, et al. Extracellular Vesicles From Human Saliva Promote Hemostasis by Delivering Coagulant Tissue Factor to Activated Platelets. J Thromb Haemost (2018) 16(6):1153-63. doi: 10.1111/jth.14023

5. Raposo G, Stoorvogel W. Extracellular Vesicles: Exosomes, Microvesicles, and Friends. J Cell Biol (2013) 200(4):373-83. doi: 10.1083/jcb.201211138

6. Doyle LM, Wang MZ. Overview of Extracellular Vesicles, Their Origin, Composition, Purpose, and Methods for Exosome Isolation and Analysis. Cells (2019) 8(7):727. doi: 10.3390/cells8070727

7. Konoshenko MY, Lekchnov EA, Vlassov AV, Laktionov PP. Isolation of Extracellular Vesicles: General Methodologies and Latest Trends. BioMed Res Int (2018) 2018:1-27. doi: 10.1155/2018/8545347

8. Théry C, Witwer KW, Aikawa E, Alcaraz MJ, Anderson JD, Andriantsitohaina R, et al. Minimal Information for Studies of Extracellular Vesicles 2018 (MISEV2018): A Position Statement of the International Society for Extracellular Vesicles and Update of the MISEV2014 Guidelines. J Extracellular Vesicles (2018) 7(1):1535750. doi: 10.1080/20013078.2018.1535750

9. van Niel G, D'Angelo G, Raposo G. Shedding Light on the Cell Biology of Extracellular Vesicles. Nat Rev Mol Cell Biol (2018) 19(4):213-28. doi: 10.1038/nrm.2017.125

10. ELA S, Mager I, Breakefield XO, Wood MJ. Extracellular Vesicles: Biology and Emerging Therapeutic Opportunities. Nat Rev Drug Discovery (2013) 12 (5):347-57. doi: 10.1038/nrd3978

11. Bobrie A, Colombo M, Krumeich S, Raposo G, Thery C. Diverse Subpopulations of Vesicles Secreted by Different Intracellular Mechanisms Are Present in Exosome Preparations Obtained by Differential Ultracentrifugation. J Extracell Vesicles (2012) 1. doi: 10.3402/jev.v1i0.18397

12. Zeng F, Morelli AE. Extracellular Vesicle-Mediated MHC Cross-Dressing in Immune Homeostasis, Transplantation, Infectious Diseases, and Cancer. Semin Immunopathol (2018) 40(5):477-90. doi: 10.1007/s00281-018-0679-8

13. Kalluri R, LeBleu VS. The Biology, Function, and Biomedical Applications of Exosomes. Science (2020) 367(6478):eaau6977. doi: 10.1126/science.aau6977

14. Stahl PD, Raposo G. Extracellular Vesicles: Exosomes and Microvesicles, Integrators of Homeostasis. Physiology (2019) 34(3):169-77. doi: 10.1152/ physiol.00045.2018

15. Edgar JR. Q\&A: What Are Exosomes, Exactly? BMC Biol (2016) 14:46. doi: $10.1186 / \mathrm{s} 12915-016-0268-\mathrm{z}$

16. Jiang L, Dong H, Cao H, Ji X, Luan S, Liu J. Exosomes in Pathogenesis, Diagnosis, and Treatment of Alzheimer's Disease. Med Sci Monit (2019) 25:3329-35. doi: 10.12659/MSM.914027

17. Console L, Scalise M, Indiveri C. Exosomes in Inflammation and Role as Biomarkers. Clin Chim Acta (2019) 488:165-71. doi: 10.1016/ j.cca.2018.11.009

\section{FUNDING}

This research was funded by Fundação de Amparo à Pesquisa do Estado de São Paulo (2019/25826-5 and 2016/03322-7); CNPq (Conselho Nacional de Desenvolvimento Científico e Tecnológico); CAPES (Coordenação de Aperfeiçoamento de Nível Superior); and Fundação de Apoio ao Ensino, Pesquisa e Assistência do Hospital das Clínicas da Faculdade de Medicina de Ribeirão Preto da Universidade de São Paulo.

18. Wu Z, Wang L, Li J, Wang L, Wu Z, Sun X. Extracellular Vesicle-Mediated Communication Within Host-Parasite Interactions. Front Immunol (2018) 9:3066. doi: 10.3389/fimmu.2018.03066

19. Pan B-T, Johnstone RM. Fate of the Transferrin Receptor During Maturation of Sheep Reticulocytes In Vitro: Selective Externalization of the Receptor. Cell (1983) 33(3):967-78. doi: 10.1016/0092-8674(83)90040-5

20. Harding C, Stahl P. Transferrin Recycling in Reticulocytes: $\mathrm{pH}$ and Iron Are Important Determinants of Ligand Binding and Processing. Biochem Biophys Res Commun (1983) 113(2):650-8. doi: 10.1016/0006-291x(83)91776-x

21. Barz D, Goppelt M, Szamel M, Schirrmacher V, Resch K. Characterization of Cellular and Extracellular Plasma Membrane Vesicles From a NonMetastasizing Lymphoma (Eb) and Its Metastasizing Variant (ESb). Biochim Biophys Acta (1985) 814(1):77-84. doi: 10.1016/0005-2736(85) 90421-3

22. Schirrmacher V, Barz D. Characterization of Cellular and Extracellular Plasma Membrane Vesicles From a Low Metastatic Lymphoma (Eb) and Its High Metastatic Variant (ESb): Inhibitory Capacity in Cell-Cell Interaction Systems. Biochim Biophys Acta (1986) 860(2):236-42. doi: 10.1016/0005-2736(86)90519-5

23. Johnstone RM, Adam M, Hammond JR, Orr L, Turbide C. Vesicle Formation During Reticulocyte Maturation. Association of Plasma Membrane Activities With Released Vesicles (Exosomes). J Biol Chem (1987) 262(19):9412-20. doi: 10.1016/S0021-9258(18)48095-7

24. Raposo G, Nijman HW, Stoorvogel W, Liejendekker R, Harding CV, Melief CJ, et al. B Lymphocytes Secrete Antigen-Presenting Vesicles. J Exp Med (1996) 183(3):1161-72. doi: 10.1084/jem.183.3.1161

25. Southam CM. The Possibilities of a Vaccine for Cancer. CA Cancer J Clin (1969) 19(3):154-7. doi: 10.3322/canjclin.19.3.154

26. JL M. Cancer Vaccine Prospects: Not Soon. Science (1974) 183(4129):1067. doi: 10.1126/science.183.4129.1067

27. Marchand M, Weynants P, Rankin E, Arienti F, Belli F, Parmiani G, et al. Tumor Regression Responses in Melanoma Patients Treated With a Peptide Encoded by Gene MAGE-3. Int J Cancer (1995) 63(6):883-5. doi: 10.1002/ ijc. 2910630622

28. Mandelboim O, Vadai E, Fridkin M, Katz-Hillel A, Feldman M, Berke G, et al. Regression of Established Murine Carcinoma Metastases Following Vaccination With Tumour-Associated Antigen Peptides. Nat Med (1995) 1 (11):1179-83. doi: $10.1038 / \mathrm{nm} 1195-1179$

29. Schmidt W, Buschle M, Zauner W, Kirlappos H, Mechtler K, Trska B, et al. Cell-Free Tumor Antigen Peptide-Based Cancer Vaccines. Proc Natl Acad Sci USA (1997) 94(7):3262-7. doi: 10.1073/pnas.94.7.3262

30. Zitvogel L, Regnault A, Lozier A, Wolfers J, Flament C, Tenza D, et al. Eradication of Established Murine Tumors Using a Novel Cell-Free Vaccine: Dendritic Cell-Derived Exosomes. Nat Med (1998) 4(5):594-600. doi: 10.1038/nm0598-594

31. Wolfers J, Lozier A, Raposo G, Regnault A, Thery C, Masurier C, et al. Tumor-Derived Exosomes Are a Source of Shared Tumor Rejection Antigens for CTL Cross-Priming. Nat Med (2001) 7(3):297-303. doi: 10.1038/85438

32. Andre F, Schartz NE, Movassagh M, Flament C, Pautier P, Morice P, et al. Malignant Effusions and Immunogenic Tumour-Derived Exosomes. Lancet (London England) (2002) 360(9329):295-305. doi: 10.1016/s0140-6736(02) 09552-1

33. Chaput N, Schartz NEC, André F, Taïeb J, Novault S, Bonnaventure P, et al. Exosomes as Potent Cell-Free Peptide-Based Vaccine. II. Exosomes in CpG 
Adjuvants Efficiently Prime Naive Tcl Lymphocytes Leading to Tumor Rejection. J Immunol (2004) 172(4):2137. doi: 10.4049/jimmunol.172.4.2137

34. André F, Chaput N, Schartz NEC, Flament C, Aubert N, Bernard J, et al. Exosomes as Potent Cell-Free Peptide-Based Vaccine. I. Dendritic Cell-Derived Exosomes Transfer Functional MHC Class I/Peptide Complexes to Dendritic Cells. J Immunol (2004) 172(4):2126. doi: 10.4049/jimmunol.172.4.2126

35. Altieri SL, Khan ANH, Tomasi TB. Exosomes From Plasmacytoma Cells as a Tumor Vaccine. J Immunotherapy (2004) 27(4):282-8. doi: 10.1097/ 00002371-200407000-00004

36. Aline F, Bout D, Amigorena S, Roingeard P, Dimier-Poisson I. Toxoplasma Gondii Antigen-Pulsed-Dendritic Cell-Derived Exosomes Induce a Protective Immune Response Against T. Gondii Infection. Infect Immun (2004) 72(7):4127-37. doi: 10.1128/IAI.72.7.4127-4137.2004

37. Ochoa-Reparaz J, Sesma B, Alvarez M, Jesus Renedo M, Irache JM, Gamazo C. Humoral Immune Response in Hens Naturally Infected With Salmonella Enteritidis Against Outer Membrane Proteins and Other Surface Structural Antigens. Vet Res (2004) 35(3):291-8. doi: 10.1051/vetres:2004011

38. Gasperini G, Alfini R, Arato V, Mancini F, Aruta MG, Kanvatirth P, et al. Salmonella Paratyphi A Outer Membrane Vesicles Displaying Vi Polysaccharide as Multivalent Vaccine Against Enteric Fever. Infect Immun (2020) 89:1-9. doi: 10.1128/iai.00699-20

39. Lamparski HG, Metha-Damani A, Yao J-Y, Patel S, Hsu D-H, Ruegg C, et al. Production and Characterization of Clinical Grade Exosomes Derived From Dendritic Cells. J Immunol Methods (2002) 270(2):211-26. doi: 10.1016/ s0022-1759(02)00330-7

40. Escudier B, Dorval T, Chaput N, Andre F, Caby MP, Novault S, et al. Vaccination of Metastatic Melanoma Patients With Autologous Dendritic Cell (DC) Derived-Exosomes: Results of Thefirst Phase I Clinical Trial. J Transl Med (2005) 3(1):10. doi: 10.1186/1479-5876-3-10

41. Morse MA, Garst J, Osada T, Khan S, Hobeika A, Clay TM, et al. A Phase I Study of Dexosome Immunotherapy in Patients With Advanced non-Small Cell Lung Cancer. J Transl Med (2005) 3(1):9. doi: 10.1186/1479-5876-3-9

42. Hao S, Liu Y, Yuan J, Zhang X, He T, Wu X, et al. Novel Exosome-Targeted CD4+ T Cell Vaccine Counteracting CD4+25+ Regulatory T Cell-Mediated Immune Suppression and Stimulating Efficient Central Memory CD8+ CTL Responses. J Immunol (2007) 179(5):2731-40. doi: 10.4049/ jimmunol.179.5.2731

43. Besse B, Charrier M, Lapierre V, Dansin E, Lantz O, Planchard D, et al. Dendritic Cell-Derived Exosomes as Maintenance Immunotherapy After First Line Chemotherapy in NSCLC. Oncoimmunology (2016) 5(4): e1071008. doi: 10.1080/2162402X.2015.1071008

44. Nanjundappa RH, Wang R, Xie Y, Umeshappa CS, Xiang J. Novel CD8+ T Cell-Based Vaccine Stimulates Gp120-Specific CTL Responses Leading to Therapeutic and Long-Term Immunity in Transgenic HLA-A2 Mice. Vaccine (2012) 30(24):3519-25. doi: 10.1016/j.vaccine.2012.03.075

45. Nassar W, El-Ansary M, Sabry D, Mostafa MA, Fayad T, Kotb E, et al. Umbilical Cord Mesenchymal Stem Cells Derived Extracellular Vesicles can Safely Ameliorate the Progression of Chronic Kidney Diseases. Biomater Res (2016) 20:21. doi: 10.1186/s40824-016-0068-0

46. Yang MQ, Du Q, Varley PR, Goswami J, Liang Z, Wang R, et al. Interferon Regulatory Factor 1 Priming of Tumour-Derived Exosomes Enhances the Antitumour Immune Response. Br J Cancer (2018) 118(1):62-71. doi: 10.1038/bjc.2017.389

47. Anticoli S, Manfredi F, Chiozzini C, Arenaccio C, Olivetta E, Ferrantelli F, et al. An Exosome-Based Vaccine Platform Imparts Cytotoxic T Lymphocyte Immunity Against Viral Antigens. Biotechnol J (2018) 13(4):e1700443. doi: 10.1002/biot.201700443

48. Zurita ME, Wilk MM, Carriquiriborde F, Bartel E, Moreno G, Misiak A, et al. A Pertussis Outer Membrane Vesicle-Based Vaccine Induces LungResident Memory CD4 T Cells and Protection Against Bordetella Pertussis, Including Pertactin Deficient Strains. Front Cell Infect Microbiol (2019) 9:125. doi: $10.3389 /$ fcimb. 2019.00125

49. Muenst S, Laubli H, Soysal SD, Zippelius A, Tzankov A, Hoeller S. The Immune System and Cancer Evasion Strategies: Therapeutic Concepts. J Intern Med (2016) 279(6):541-62. doi: 10.1111/joim.12470

50. Liu Y, Cao X. Immunosuppressive Cells in Tumor Immune Escape and Metastasis. J Mol Med (Berl) (2016) 94(5):509-22. doi: 10.1007/s00109-015-1376-x
51. Moore C, Kosgodage U, Lange S, Inal JM. The Emerging Role of Exosome and Microvesicle- (EMV-) Based Cancer Therapeutics and Immunotherapy. Int J Cancer (2017) 141(3):428-36. doi: 10.1002/ijc.30672

52. Xu Z, Zeng S, Gong Z, Yan Y. Exosome-Based Immunotherapy: A Promising Approach for Cancer Treatment. Mol Cancer (2020) 19(1):160. doi: 10.1186/s12943-020-01278-3

53. DeMaria PJ, Bilusic M. Cancer Vaccines. Hematology/Oncology Clinics North America (2019) 33(2):199-214. doi: 10.1016/j.hoc.2018.12.001

54. Tagliamonte M, Petrizzo A, Tornesello ML, Buonaguro FM, Buonaguro L. Antigen-Specific Vaccines for Cancer Treatment. Hum Vaccines Immunotherapeutics (2014) 10(11):3332-46. doi: 10.4161/21645515.2014.973317

55. Roudko V, Greenbaum B, Bhardwaj N. Computational Prediction and Validation of Tumor-Associated Neoantigens. Front Immunol (2020) 11:27:1-11. doi: 10.3389/fimmu.2020.00027

56. Lopes A, Vandermeulen G, Préat V. Cancer DNA Vaccines: Current Preclinical and Clinical Developments and Future Perspectives. J Exp Clin Cancer Res (2019) 38(1):1-24. doi: 10.1186/s13046-019-1154-7

57. Thomas S, Prendergast GC. Cancer Vaccines: A Brief Overview. Methods Mol Biol (2016) 1403:755-61. doi: 10.1007/978-1-4939-3387-7_43

58. Gatti-Mays ME, Redman JM, Collins JM, Bilusic M. Cancer Vaccines: Enhanced Immunogenic Modulation Through Therapeutic Combinations. Hum Vaccines Immunotherapeutics (2017) 13(11):2561-74. doi: 10.1080/ 21645515.2017.1364322

59. Dillman RO. Is There a Role for Therapeutic Cancer Vaccines in the Age of Checkpoint Inhibitors? Hum Vaccines Immunotherapeutics (2016) 13 (3):528-32. doi: 10.1080/21645515.2016.1244149

60. Melief CJ, van Hall T, Arens R, Ossendorp F, van der Burg SH. Therapeutic Cancer Vaccines. J Clin Invest (2015) 125(9):3401-12. doi: 10.1172/JCI80009

61. Yang Y. Cancer Immunotherapy: Harnessing the Immune System to Battle Cancer. J Clin Invest (2015) 125(9):3335-7. doi: 10.1172/JCI83871

62. Bowen WS, Svrivastava AK, Batra L, Barsoumian H, Shirwan H. Current Challenges for Cancer Vaccine Adjuvant Development. Expert Rev Vaccines (2018) 17(3):207-15. doi: 10.1080/14760584.2018.1434000

63. Temizoz B, Kuroda E, Ishii KJ. Vaccine Adjuvants as Potential Cancer Immunotherapeutics. Int Immunol (2016) 28(7):329-38. doi: 10.1093/ intimm/dxw015

64. Harari A, Graciotti M, Bassani-Sternberg M, Kandalaft LE. Antitumour Dendritic Cell Vaccination in a Priming and Boosting Approach. Nat Rev Drug Discovery (2020) 19(9):635-52. doi: 10.1038/s41573-020-0074-8

65. Morishita M, Takahashi Y, Matsumoto A, Nishikawa M, Takakura Y. Exosome-Based Tumor Antigens-Adjuvant Co-Delivery Utilizing Genetically Engineered Tumor Cell-Derived Exosomes With Immunostimulatory CpG DNA. Biomaterials (2016) 111:55-65. doi: 10.1016/j.biomaterials.2016.09.031

66. Pitt JM, Andre F, Amigorena S, Soria JC, Eggermont A, Kroemer G, et al. Dendritic Cell-Derived Exosomes for Cancer Therapy. J Clin Invest (2016) 126(4):1224-32. doi: 10.1172/JCI81137

67. Andre F, Escudier B, Angevin E, Tursz T, Zitvogel L. Exosomes for Cancer Immunotherapy. Ann Oncol (2004) 15 Suppl 4:iv141-4. doi: 10.1093/ annonc/mdh918

68. Viaud S, Thery C, Ploix S, Tursz T, Lapierre V, Lantz O, et al. Dendritic CellDerived Exosomes for Cancer Immunotherapy: What's Next? Cancer Res (2010) 70(4):1281-5. doi: 10.1158/0008-5472.CAN-09-3276

69. Fu C, Zhou L, Mi QS, Jiang A. DC-Based Vaccines for Cancer Immunotherapy. Vaccines (Basel) (2020) 8(4):1-16. doi: 10.3390/vaccines 8040706

70. Wahlund CJE, Gucluler G, Hiltbrunner S, Veerman RE, Naslund TI, Gabrielsson S. Exosomes From Antigen-Pulsed Dendritic Cells Induce Stronger Antigen-Specific Immune Responses Than Microvesicles In Vivo. Sci Rep (2017) 7(1):17095. doi: 10.1038/s41598-017-16609-6

71. Lu Z, Zuo B, Jing R, Gao X, Rao Q, Liu Z, et al. Dendritic Cell-Derived Exosomes Elicit Tumor Regression in Autochthonous Hepatocellular Carcinoma Mouse Models. J Hepatol (2017) 67(4):739-48. doi: 10.1016/ j.jhep.2017.05.019

72. Seo N, Akiyoshi K, Shiku H. Exosome-Mediated Regulation of Tumor Immunology. Cancer Sci (2018) 109(10):2998-3004. doi: 10.1111/cas.13735

73. Tkach M, Kowal J, Zucchetti AE, Enserink L, Jouve M, Lankar D, et al. Qualitative Differences in T-Cell Activation by Dendritic Cell-Derived 
Extracellular Vesicle Subtypes. EMBO J (2017) 36(20):3012-28. doi: $10.15252 / \mathrm{embj} .201696003$

74. Hao S, Bai O, Li F, Yuan J, Laferte S, Xiang J. Mature Dendritic Cells Pulsed With Exosomes Stimulate Efficient Cytotoxic T-Lymphocyte Responses and Antitumour Immunity. Immunology (2007) 120(1):90-102. doi: 10.1111/ j.1365-2567.2006.02483.x

75. Qazi KR, Gehrmann U, Domange Jordö E, Karlsson MCI, Gabrielsson S. Antigen-Loaded Exosomes Alone Induce Th1-Type Memory Through a B Cell-Dependent Mechanism. Blood (2009) 113(12):2673-83. doi: 10.1182/ blood-2008-04-153536

76. Hao S, Yuan J, Xiang J. Nonspecific Cd4+T Cells With Uptake of AntigenSpecific Dendritic Cell-Released Exosomes Stimulate Antigen-Specific CD8 +CTL Responses and Long-Term T Cell Memory. J Leukocyte Biol (2007) 82 (4):829-38. doi: 10.1189/jlb.0407249

77. Viaud S, Ploix S, Lapierre V, Théry C, Commere P-H, Tramalloni D, et al. Updated Technology to Produce Highly Immunogenic Dendritic CellDerived Exosomes of Clinical Grade. J Immunotherapy (2011) 34(1):6575. doi: 10.1097/CJI.0b013e3181fe535b

78. Phung CD, Pham TT, Nguyen HT, Nguyen TT, Ou W, Jeong JH, et al. AntiCTLA-4 Antibody-Functionalized Dendritic Cell-Derived Exosomes Targeting Tumor-Draining Lymph Nodes for Effective Induction of Antitumor T-Cell Responses. Acta Biomater (2020) 115:371-82. doi: 10.1016/j.actbio.2020.08.008

79. Xie Y, Wang L, Freywald A, Qureshi M, Chen Y, Xiang J. A Novel T CellBased Vaccine Capable of Stimulating Long-Term Functional CTL Memory Against B16 Melanoma via CD40L Signaling. Cell Mol Immunol (2012) 10 (1):72-7. doi: $10.1038 / \mathrm{cmi} .2012 .37$

80. Nakayama M. Antigen Presentation by MHC-Dressed Cells. Front Immunol (2015) 5:672:1-8. doi: 10.3389/fimmu.2014.00672

81. Montecalvo A, Shufesky WJ, Beer Stolz D, Sullivan MG, Wang Z, Divito SJ, et al. Exosomes As a Short-Range Mechanism to Spread Alloantigen Between Dendritic Cells During T Cell Allorecognition. J Immunol (2008) 180(5):3081-90. doi: 10.4049/jimmunol.180.5.3081

82. Pitt JM, Charrier M, Viaud S, André F, Besse B, Chaput N, et al. Dendritic Cell-Derived Exosomes as Immunotherapies in the Fight Against Cancer. J Immunol (2014) 193(3):1006-11. doi: 10.4049/jimmunol.1400703

83. Campana S, De Pasquale C, Carrega P, Ferlazzo G, Bonaccorsi I. CrossDressing: An Alternative Mechanism for Antigen Presentation. Immunol Lett (2015) 168(2):349-54. doi: 10.1016/j.imlet.2015.11.002

84. Vincent-Schneider H. Exosomes Bearing HLA-DR1 Molecules Need Dendritic Cells to Efficiently Stimulate Specific T Cells. Int Immunol (2002) 14(7):713-22. doi: 10.1093/intimm/dxf048

85. Naslund TI, Gehrmann U, Qazi KR, Karlsson MC, Gabrielsson S. Dendritic Cell-Derived Exosomes Need to Activate Both T and B Cells to Induce Antitumor Immunity. J Immunol (2013) 190(6):2712-9. doi: 10.4049/ jimmunol.1203082

86. Nikfarjam S, Rezaie J, Kashanchi F, Jafari R. Dexosomes as a Cell-Free Vaccine for Cancer Immunotherapy. J Exp Clin Cancer Res (2020) 39(1):120. doi: 10.1186/s13046-020-01781-x

87. Admyre C, Johansson SM, Paulie S, Gabrielsson S. Direct Exosome Stimulation of Peripheral humanT Cells Detected by ELISPOT. Eur J Immunol (2006) 36(7):1772-81. doi: 10.1002/eji.200535615

88. Robbins PD, Morelli AE. Regulation of Immune Responses by Extracellular Vesicles. Nat Rev Immunol (2014) 14(3):195-208. doi: 10.1038/nri3622

89. Jang GY, Lee JW, Kim YS, Lee SE, Han HD, Hong KJ, et al. Interactions Between Tumor-Derived Proteins and Toll-Like Receptors. Exp Mol Med (2020) 52:1926-35. doi: 10.1038/s12276-020-00540-4

90. Patidar A, Selvaraj S, Sarode A, Chauhan P, Chattopadhyay D, Saha B. DAMP-TLR-Cytokine Axis Dictates the Fate of Tumor. Cytokine (2018) 104:114-23. doi: 10.1016/j.cyto.2017.10.004

91. Damo M, Wilson DS, Simeoni E, Hubbell JA. TLR-3 Stimulation Improves Anti-Tumor Immunity Elicited by Dendritic Cell Exosome-Based Vaccines in a Murine Model of Melanoma. Sci Rep (2015) 5:17622. doi: 10.1038/ srep 17622

92. Zhong X, Zhou Y, Cao Y, Ding J, Wang P, Luo Y, et al. Enhanced Antitumor Efficacy Through Microwave Ablation Combined With a Dendritic CellDerived Exosome Vaccine in Hepatocellular Carcinoma. Int J Hyperthermia (2020) 37(1):1210-8. doi: 10.1080/02656736.2020.1836406
93. Kim KI, Chung HK, Park JH, Lee YJ, Kang JH. Alpha-Fetoprotein-Targeted Reporter Gene Expression Imaging in Hepatocellular Carcinoma. World J Gastroenterol (2016) 22(27):6127-34. doi: 10.3748/wjg.v22.i27.6127

94. Zimmer J, Simhadri VR, Reiners KS, Hansen HP, Topolar D, Simhadri VL, et al. Dendritic Cells Release HLA-B-Associated Transcript-3 Positive Exosomes to Regulate Natural Killer Function. PloS One (2008) 3(10): e3377. doi: 10.1371/journal.pone.0003377

95. Munich S, Sobo-Vujanovic A, Buchser WJ, Beer-Stolz D, Vujanovic NL. Dendritic Cell Exosomes Directly Kill Tumor Cells and Activate Natural Killer Cells via TNF Superfamily Ligands. OncoImmunology (2014) 1 (7):1074-83. doi: 10.4161/onci.20897

96. Reiners KS, Dassler J, Coch C, Pogge von Strandmann E. Role of Exosomes Released by Dendritic Cells and/or by Tumor Targets: Regulation of NK Cell Plasticity. Front Immunol (2014) 5:91:1-5. doi: 10.3389/fimmu.2014.00091

97. Valadi H, Ekström K, Bossios A, Sjöstrand M, Lee JJ, Lötvall JO. ExosomeMediated Transfer of mRNAs and microRNAs Is a Novel Mechanism of Genetic Exchange Between Cells. Nat Cell Biol (2007) 9(6):654-9. doi: $10.1038 /$ ncb1596

98. Liang Y, Song X, Li Y, Chen B, Zhao W, Wang L, et al. LncRNA BCRT1 Promotes Breast Cancer Progression by Targeting miR-1303/PTBP3 Axis. Mol Cancer (2020) 19(1):1-20. doi: 10.1186/s12943-020-01206-5

99. Duvallet E, Boulpicante M, Yamazaki T, Daskalogianni C, Prado Martins R, Baconnais S, et al. Exosome-Driven Transfer of Tumor-Associated Pioneer Translation Products (TA-PTPs) for the MHC Class I Cross-Presentation Pathway. OncoImmunology (2016) 5(9):e1198865. doi: 10.1080/ 2162402x.2016.1198865

100. Labani-Motlagh A, Naseri S, Wenthe J, Eriksson E, Loskog A. Systemic Immunity Upon Local Oncolytic Virotherapy Armed With Immunostimulatory Genes may be Supported by Tumor-Derived Exosomes. Mol Ther - Oncolytics (2021) 20:508-18. doi: 10.1016/j.omto. 2021.02.007

101. Fanini F, Fabbri M. Cancer-Derived Exosomic microRNAs Shape the Immune System Within the Tumor Microenvironment: State of the Art. Semin Cell Dev Biol (2017) 67:23-8. doi: 10.1016/j.semcdb.2016.12.004

102. Sharma RK, Yolcu ES, Shirwan H. SA-4-1BBL as a Novel Adjuvant for the Development of Therapeutic Cancer Vaccines. Expert Rev Vaccines (2014) 13(3):387-98. doi: 10.1586/14760584.2014.880340

103. Huang S, He X, Wang P, Wang L, Wu J, Shi G, et al. Extracellular Vesicles Long RNA Sequencing Reveals Abundant mRNA, circRNA, and lncRNA in Human Blood as Potential Biomarkers for Cancer Diagnosis. Clin Chem (2019) 65(6):798-808. doi: 10.1373/clinchem.2018.301291

104. Li H, Xiong H-G, Xiao Y, Yang Q-C, Yang S-C, Tang H-C, et al. Long NonCoding RNA LINC02195 as a Regulator of MHC I Molecules and Favorable Prognostic Marker for Head and Neck Squamous Cell Carcinoma. Front Oncol (2020) 10:615:1-12. doi: 10.3389/fonc.2020.00615

105. Zhang G, Fan E, Zhong Q, Feng G, Shuai Y, Wu M, et al. Identification and Potential Mechanisms of a 4-lncRNA Signature That Predicts Prognosis in Patients With Laryngeal Cancer. Hum Genomics (2019) 13(1):1-10. doi: 10.1186/s40246-019-0230-6

106. Gu X, Erb U, Buchler MW, Zoller M. Improved Vaccine Efficacy of Tumor Exosome Compared to Tumor Lysate Loaded Dendritic Cells in Mice. Int $J$ Cancer (2015) 136(4):E74-84. doi: 10.1002/ijc.29100

107. Wang C, Huang X, Wu Y, Wang J, Li F, Guo G. Tumor Cell-Associated Exosomes Robustly Elicit Anti-Tumor Immune Responses Through Modulating Dendritic Cell Vaccines in Lung Tumor. Int J Biol Sci (2020) 16(4):633-43. doi: 10.7150/ijbs.38414

108. Yao Y, Wang C, Wei W, Shen C, Deng X, Chen L, et al. Dendritic Cells Pulsed With Leukemia Cell-Derived Exosomes More Efficiently Induce Antileukemic Immunities. PloS One (2014) 9(3):e91463. doi: 10.1371/ journal.pone.0091463

109. Xiao L, Erb U, Zhao K, Hackert T, Zoller M. Efficacy of Vaccination With Tumor-Exosome Loaded Dendritic Cells Combined With Cytotoxic Drug Treatment in Pancreatic Cancer. Oncoimmunology (2017) 6(6):e1319044. doi: 10.1080/2162402X.2017.1319044

110. Huang F, Wan J, Hao S, Deng X, Chen L, Ma L. TGF-Beta1-Silenced Leukemia Cell-Derived Exosomes Target Dendritic Cells to Induce Potent Anti-Leukemic Immunity in a Mouse Model. Cancer Immunol Immunother (2017) 66(10):1321-31. doi: 10.1007/s00262-017-2028-5 
111. Liu H, Chen L, Liu J, Meng H, Zhang R, Ma L, et al. Co-Delivery of TumorDerived Exosomes With Alpha-Galactosylceramide on Dendritic Cell-Based Immunotherapy for Glioblastoma. Cancer Lett (2017) 411:182-90. doi: 10.1016/j.canlet.2017.09.022

112. Zhang Y, Luo CL, He BC, Zhang JM, Cheng G, Wu XH. Exosomes Derived From IL-12-Anchored Renal Cancer Cells Increase Induction of Specific Antitumor Response In Vitro: A Novel Vaccine for Renal Cell Carcinoma. Int J Oncol (2010) 36(1):133-40. doi: 10.3892/ijo_00000484

113. Yang D, Postnikov YV, Li Y, Tewary P, de la Rosa G, Wei F, et al. HighMobility Group Nucleosome-Binding Protein 1 Acts as an Alarmin and Is Critical for Lipopolysaccharide-Induced Immune Responses. J Exp Med (2012) 209(1):157-71. doi: 10.1084/jem.20101354

114. Alam MM, Yang, Trivett A, Meyer TJ, Oppenheim JJ. HMGN1 and R848 Synergistically Activate Dendritic Cells Using Multiple Signaling Pathways. Front Immunol (2018) 9:2982. doi: 10.3389/fimmu.2018.02982

115. Zuo B, Qi H, Lu Z, Chen L, Sun B, Yang R, et al. Alarmin-Painted Exosomes Elicit Persistent Antitumor Immunity in Large Established Tumors in Mice. Nat Commun (2020) 11(1):1790. doi: 10.1038/s41467-020-15569-2

116. Whiteside TL. Exosomes and Tumor-Mediated Immune Suppression. J Clin Invest (2016) 126(4):1216-23. doi: 10.1172/JCI81136

117. Chen Z, You L, Wang L, Huang X, Liu H, Wei JY, et al. Dual Effect of DLBCL-Derived EXOs in Lymphoma to Improve DC Vaccine Efficacy. Vitro while favor tumorgenesis vivo. J Exp Clin Cancer Res (2018) 37(1):190. doi: 10.1186/s13046-018-0863-7

118. Théry C, Ostrowski M, Segura E. Membrane Vesicles as Conveyors of Immune Responses. Nat Rev Immunol (2009) 9(8):581-93. doi: 10.1038/ nri2567

119. Xie F, Xu M, Lu J, Mao L, Wang S. The Role of Exosomal PD-L1 in Tumor Progression and Immunotherapy. Mol Cancer (2019) 18(1):1-10. doi: 10.1186/s12943-019-1074-3

120. Yu S, Liu C, Su K, Wang J, Liu Y, Zhang L, et al. Tumor Exosomes Inhibit Differentiation of Bone Marrow Dendritic Cells. J Immunol (2007) 178 (11):6867-75. doi: 10.4049/jimmunol.178.11.6867

121. Ning Y, Shen K, Wu Q, Sun X, Bai Y, Xie Y, et al. Tumor Exosomes Block Dendritic Cells Maturation to Decrease the T Cell Immune Response. Immunol Lett (2018) 199:36-43. doi: 10.1016/j.imlet.2018.05.002

122. Liu Y, Yin Z, Lu P, Ma Y, Luo B, Xiang L, et al. Lung Carcinoma Cells Secrete Exosomal MALAT1 to Inhibit Dendritic Cell Phagocytosis, Inflammatory Response, Costimulatory Molecule Expression and Promote Dendritic Cell Autophagy via AKT/mTOR Pathway. OncoTargets Ther (2020) 13:10693705. doi: $10.2147 /$ ott.s256669

123. Li K, Chen Y, Li A, Tan C, Liu X. Exosomes Play Roles in Sequential Processes of Tumor Metastasis. Int J Cancer (2018) 144(7):1486-95. doi: 10.1002/ijc.31774

124. Kahlert C, Kalluri R. Exosomes in Tumor Microenvironment Influence Cancer Progression and Metastasis. J Mol Med (2013) 91(4):431-7. doi: 10.1007/s00109-013-1020-6

125. Mashouri L, Yousefi H, Aref AR, Ahadi AM, Molaei F, Alahari SK. Exosomes: Composition, Biogenesis, and Mechanisms in Cancer Metastasis and Drug Resistance. Mol Cancer (2019) 18(1):1-14. doi: 10.1186/s12943-019-0991-5

126. Shi X, Sun J, Li H, Lin H, Xie W, Li J, et al. Antitumor Efficacy of InterferonGamma-Modified Exosomal Vaccine in Prostate Cancer. Prostate (2020) 80 (11):811-23. doi: 10.1002/pros.23996

127. Kitai Y, Kawasaki T, Sueyoshi T, Kobiyama K, Ishii KJ, Zou J, et al. DNAContaining Exosomes Derived From Cancer Cells Treated With Topotecan Activate a STING-Dependent Pathway and Reinforce Antitumor Immunity. J Immunol (2017) 198(4):1649-59. doi: 10.4049/jimmunol.1601694

128. Fu C, Peng P, Loschko J, Feng L, Pham P, Cui W, et al. Plasmacytoid Dendritic Cells Cross-Prime Naive CD8 T Cells by Transferring Antigen to Conventional Dendritic Cells Through Exosomes. Proc Natl Acad Sci (2020) 117(38):23730-41. doi: 10.1073/pnas.2002345117

129. Liu Q, Fan T, Zheng Y, Yang S-1, Yu Z, Duo Y, et al. Immunogenic ExosomeEncapsulated Black Phosphorus Nanoparticles as an Effective Anticancer Photo-Nanovaccine. Nanoscale (2020) 12(38):19939-52. doi: 10.1039/ d0nr05953f

130. Xie Y, Wu J, Xu A, Ahmeqd S, Sami A, Chibbar R, et al. Heterologous Human/Rat HER2-Specific Exosome-Targeted T Cell Vaccine Stimulates
Potent Humoral and CTL Responses Leading to Enhanced Circumvention of HER2 Tolerance in Double Transgenic HLA-A2/HER2 Mice. Vaccine (2018) 36(11):1414-22. doi: 10.1016/j.vaccine.2018.01.078

131. Zhang H, Tang K, Zhang Y, Ma R, Ma J, Li Y, et al. Cell-Free Tumor Microparticle Vaccines Stimulate Dendritic Cells via cGAS/STING Signaling. Cancer Immunol Res (2015) 3(2):196-205. doi: 10.1158/23266066.cir-14-0177

132. Lv L-H, Wan Y-L, Lin Y, Zhang W, Yang M, Li G-L, et al. Anticancer Drugs Cause Release of Exosomes With Heat Shock Proteins From Human Hepatocellular Carcinoma Cells That Elicit Effective Natural Killer Cell Antitumor Responses in Vitro. J Biol Chem (2012) 287(19):15874-85. doi: 10.1074/jbc.M112.340588

133. Taghikhani A, Hassan ZM, Ebrahimi M, Moazzeni SM. microRNA Modified Tumor-Derived Exosomes as Novel Tools for Maturation of Dendritic Cells. J Cell Physiol (2018) 234(6):9417-27. doi: 10.1002/jcp.27626

134. Schorey JS, Harding CV. Extracellular Vesicles and Infectious Diseases: New Complexity to an Old Story. J Clin Invest (2016) 126(4):1181-9. doi: 10.1172/ JCI81132

135. Martins ST, Alves LR. Extracellular Vesicles in Viral Infections: Two Sides of the Same Coin? Front Cell Infect Microbiol (2020) 10:593170. doi: 10.3389/ fcimb. 2020.593170

136. Gould SJ, Booth AM, Hildreth JE. The Trojan Exosome Hypothesis. Proc Natl Acad Sci USA (2003) 100(19):10592-7. doi: 10.1073/pnas.1831413100

137. Teow SY, Nordin AC, Ali SA, Khoo AS. Exosomes in Human Immunodeficiency Virus Type I Pathogenesis: Threat or Opportunity? Adv Virol (2016) 2016:9852494. doi: 10.1155/2016/9852494

138. Nanjundappa RH, Wang R, Xie Y, Umeshappa CS, Chibbar R, Wei Y, et al. GP120-Specific Exosome-Targeted T Cell-Based Vaccine Capable of Stimulating DC- and CD4(+) T-Independent CTL Responses. Vaccine (2011) 29(19):3538-47. doi: 10.1016/j.vaccine.2011.02.095

139. Wang R, Xu A, Zhang X, Wu J, Freywald A, Xu J, et al. Novel ExosomeTargeted T-Cell-Based Vaccine Counteracts T-Cell Anergy and Converts CTL Exhaustion in Chronic Infection via CD40L Signaling Through the Mtorc1 Pathway. Cell Mol Immunol (2017) 14(6):529-45. doi: 10.1038/ cmi.2016.23

140. Waheed AA, Freed EO. HIV Type 1 Gag as a Target for Antiviral Therapy. AIDS Res Hum Retroviruses (2012) 28(1):54-75. doi: 10.1089/AID.2011.0230

141. Basmaciogullari S, Pizzato M. The Activity of Nef on HIV-1 Infectivity. Front Microbiol (2014) 5:232. doi: 10.3389/fmicb.2014.00232

142. Ferrantelli F, Manfredi F, Chiozzini C, Anticoli S, Olivetta E, Arenaccio C, et al. DNA Vectors Generating Engineered Exosomes Potential CTL Vaccine Candidates Against AIDS, Hepatitis B, and Tumors. Mol Biotechnol (2018) 60(11):773-82. doi: 10.1007/s12033-018-0114-3

143. Chiozzini C, Manfredi F, Arenaccio C, Ferrantelli F, Leone P. Federico M. NTerminal Fatty Acids of NEF(MUT) Are Required for the CD8(+) T-Cell Immunogenicity of In Vivo Engineered Extracellular Vesicles. Vaccines (Basel) (2020) 8(2):1-11. doi: 10.3390/vaccines 8020243

144. Li S, Li S, Wu S, Chen L. Exosomes Modulate the Viral Replication and Host Immune Responses in HBV Infection. BioMed Res Int (2019) 2019:2103943. doi: $10.1155 / 2019 / 2103943$

145. Arzumanyan A, Reis HM, Feitelson MA. Pathogenic Mechanisms in HBVand HCV-Associated Hepatocellular Carcinoma. Nat Rev Cancer (2013) 13 (2):123-35. doi: 10.1038/nrc3449

146. Yang Y, Han Q, Hou Z, Zhang C, Tian Z, Zhang J. Exosomes Mediate Hepatitis B Virus (HBV) Transmission and NK-Cell Dysfunction. Cell Mol Immunol (2017) 14(5):465-75. doi: 10.1038/cmi.2016.24

147. Wang J, Cao D, Yang J. Exosomes in Hepatitis B Virus Transmission and Related Immune Response. Tohoku J Exp Med (2020) 252(4):309-20. doi: $10.1620 /$ tjem.252.309

148. Bandopadhyay M, Bharadwaj M. Exosomal miRNAs in Hepatitis B Virus Related Liver Disease: A New Hope for Biomarker. Gut Pathog (2020) 12:23. doi: 10.1186/s13099-020-00353-w

149. Jesus S, Soares E, Cruz MT, Borges O. Exosomes as Adjuvants for the Recombinant Hepatitis B Antigen: First Report. Eur J Pharm Biopharm (2018) 133:1-11. doi: 10.1016/j.ejpb.2018.09.029

150. Krammer F, Smith GJD, Fouchier RAM, Peiris M, Kedzierska K, Doherty PC, et al. Influenza. Nat Rev Dis Primers (2018) 4(1):3. doi: 10.1038/s41572018-0002-y 
151. Keshavarz M, Mirzaei H, Salemi M, Momeni F, Mousavi MJ, Sadeghalvad M, et al. Influenza Vaccine: Where Are We and Where Do We Go? Rev Med Virol (2019) 29(1):e2014. doi: 10.1002/rmv.2014

152. Jiang Y, Cai X, Yao J, Guo H, Yin L, Leung W, et al. Role of Extracellular Vesicles in Influenza Virus Infection. Front Cell Infect Microbiol (2020) 10:366. doi: $10.3389 /$ fcimb.2020.00366

153. Bedford JG, Infusini G, Dagley LF, Villalon-Letelier F, Zheng MZM, BennettWood V, et al. Airway Exosomes Released During Influenza Virus Infection Serve as a Key Component of the Antiviral Innate Immune Response. Front Immunol (2020) 11:887. doi: 10.3389/fimmu.2020.00887

154. Hutchinson EC, Charles PD, Hester SS, Thomas B, Trudgian D, MartinezAlonso M, et al. Conserved and Host-Specific Features of Influenza Virion Architecture. Nat Commun (2014) 5:4816. doi: 10.1038/ncomms5816

155. Maemura T, Fukuyama S, Sugita Y, Lopes TJS, Nakao T, Noda T, et al. LungDerived Exosomal miR-483-3p Regulates the Innate Immune Response to Influenza Virus Infection. J Infect Dis (2018) 217(9):1372-82. doi: 10.1093/ infdis/jiy035

156. Maemura T, Fukuyama S, Kawaoka Y. High Levels of miR-483-3p Are Present in Serum Exosomes Upon Infection of Mice With Highly Pathogenic Avian Influenza Virus. Front Microbiol (2020) 11:144. doi: 10.3389/ fmicb. 2020.00144

157. Coelho C, Casadevall A. Answers to Naysayers Regarding Microbial Extracellular Vesicles. Biochem Soc Trans (2019) 47(4):1005-12. doi: 10.1042/BST20180252

158. Carvalho AL, Fonseca S, Miquel-Clopes A, Cross K, Kok KS, Wegmann U, et al. Bioengineering Commensal Bacteria-Derived Outer Membrane Vesicles for Delivery of Biologics to the Gastrointestinal and Respiratory Tract. J Extracell Vesicles (2019) 8(1):1632100. doi: 10.1080/20013078. 2019.1632100

159. Lee TY, Kim CU, Bae EH, Seo SH, Jeong DG, Yoon SW, et al. Outer Membrane Vesicles Harboring Modified Lipid A Moiety Augment the Efficacy of an Influenza Vaccine Exhibiting Reduced Endotoxicity in a Mouse Model. Vaccine (2017) 35(4):586-95. doi: 10.1016/j.vaccine. 2016.12.025

160. Watkins HC, Pagan CL, Childs HR, Posada S, Chau A, Rios J, et al. A Single Dose and Long Lasting Vaccine Against Pandemic Influenza Through the Controlled Release of a Heterospecies Tandem M2 Sequence Embedded Within Detoxified Bacterial Outer Membrane Vesicles. Vaccine (2017) 35 (40):5373-80. doi: 10.1016/j.vaccine.2017.08.013

161. Behrouzi A, Bouzari S, Siadat SD, Oloomi M, Davari M, Mazaheri H. Evaluation of the Immunogenic Property of NT H. Influenzae Protein D With Neisseria Meningitidis OMV in BALB/C.J Infect Dev Ctries (2016) 10 (12):1345-51. doi: 10.3855/jidc.7513

162. Fuhrmann G, Neuer AL, Herrmann IK. Extracellular Vesicles - A Promising Avenue for the Detection and Treatment of Infectious Diseases? Eur J Pharmaceutics Biopharm (2017) 118:56-61. doi: 10.1016/j.ejpb.2017.04.005

163. Dagnelie MA, Corvec S, Khammari A, Dréno B. Bacterial Extracellular Vesicles: A New Way to Decipher Host-Microbiota Communications in Inflammatory Dermatoses. Exp Dermatol (2019) 29(1):22-8. doi: 10.1111/ exd. 14050

164. Liu Z, Liu S, Shu Y, Yang Z, Peng B, Xu H, et al. Severe Bordetella Pertussis Infection and Vaccine Issue in Chongqing, From 2012 to 2018. Int J Infect Dis (2019) 84:102-8. doi: 10.1016/j.ijid.2019.05.014

165. Esposito S, Stefanelli P, Fry NK, Fedele G, He Q, Paterson P, et al. Pertussis Prevention: Reasons for Resurgence, and Differences in the Current Acellular Pertussis Vaccines. Front Immunol (2019) 10:1344. doi: 10.3389/ fimmu.2019.01344

166. Asensio CJ, Gaillard ME, Moreno G, Bottero D, Zurita E, Rumbo M, et al. Outer Membrane Vesicles Obtained From Bordetella Pertussis Tohama Expressing the Lipid A Deacylase PagL as a Novel Acellular Vaccine Candidate. Vaccine (2011) 29(8):1649-56. doi: 10.1016/j.vaccine.2010.12.068

167. Ormazabal M, Bartel E, Gaillard ME, Bottero D, Errea A, Zurita ME, et al. Characterization of the Key Antigenic Components of Pertussis Vaccine Based on Outer Membrane Vesicles. Vaccine (2014) 32(46):6084-90. doi: $10.1016 /$ j.vaccine.2014.08.084

168. Hozbor DF. Outer Membrane Vesicles: An Attractive Candidate for Pertussis Vaccines. Expert Rev Vaccines (2017) 16(3):193-6. doi: 10.1080/ 14760584.2017.1276832
169. Wang X, Thompson CD, Weidenmaier C, Lee JC. Release of Staphylococcus Aureus Extracellular Vesicles and Their Application as a Vaccine Platform. Nat Commun (2018) 9(1):1-13. doi: 10.1038/s41467-018-03847-z

170. Mehanny M, Koch M, Lehr C-M, Fuhrmann G. Streptococcal Extracellular Membrane Vesicles Are Rapidly Internalized by Immune Cells and Alter Their Cytokine Release. Front Immunol (2020) 11:80:1-13. doi: 10.3389/ fimmu.2020.00080

171. Sasai M, Yamamoto M. Innate, Adaptive, and Cell-Autonomous Immunity Against Toxoplasma Gondii Infection. Exp Mol Med (2019) 51(12):1-10. doi: 10.1038/s12276-019-0353-9

172. Assolini JP, Concato VM, Goncalves MD, Carloto ACM, Conchon-Costa I, Pavanelli WR, et al. Nanomedicine Advances in Toxoplasmosis: Diagnostic, Treatment, and Vaccine Applications. Parasitol Res (2017) 116(6):1603-15. doi: 10.1007/s00436-017-5458-2

173. Beauvillain C, Ruiz S, Guiton R, Bout D, Dimier-Poisson I. A Vaccine Based on Exosomes Secreted by a Dendritic Cell Line Confers Protection Against T. Gondii Infection in Syngeneic and Allogeneic Mice. Microbes Infect (2007) 9 (14-15):1614-22. doi: 10.1016/j.micinf.2007.07.002

174. Jung BK, Kim ED, Song H, Chai JY, Seo KY. Immunogenicity of Exosomes From Dendritic Cells Stimulated With Toxoplasma Gondii Lysates in Ocularly Immunized Mice. Korean J Parasitol (2020) 58(2):185-9. doi: $10.3347 / \mathrm{kjp} .2020 .58 .2 .185$

175. LoVerde PT. Schistosomiasis. Adv Exp Med Biol (2019) 1154:45-70. doi: 10.1007/978-3-030-18616-6_3

176. Sotillo J, Pearson M, Potriquet J, Becker L, Pickering D, Mulvenna J, et al. Extracellular Vesicles Secreted by Schistosoma Mansoni Contain Protein Vaccine Candidates. Int J Parasitol (2016) 46(1):1-5. doi: 10.1016/j.ijpara.2015.09.002

177. Nowacki FC, Swain MT, Klychnikov OI, Niazi U, Ivens A, Quintana JF, et al. Protein and Small Non-Coding RNA-Enriched Extracellular Vesicles Are Released by the Pathogenic Blood Fluke Schistosoma Mansoni. J Extracell Vesicles (2015) 4:28665. doi: 10.3402/jev.v4.28665

178. Samoil V, Dagenais M, Ganapathy V, Aldridge J, Glebov A, Jardim A, et al. Vesicle-Based Secretion in Schistosomes: Analysis of Protein and microRNA (miRNA) Content of Exosome-Like Vesicles Derived From Schistosoma Mansoni. Sci Rep (2018) 8(1):3286. doi: 10.1038/s41598-018-21587-4

179. Rezakhani L, Kelishadrokhi AF, Soleimanizadeh A, Rahmati S. Mesenchymal Stem Cell (MSC)-Derived Exosomes as a Cell-Free Therapy for Patients Infected With COVID-19: Real Opportunities and Range of Promises. Chem Phys Lipids (2021) 234:105009. doi: 10.1016/j.chemphyslip.2020.105009

180. Narita M, Kanda T, Abe T, Uchiyama T, Iwafuchi M, Zheng Z, et al. Immune Responses in Patients With Esophageal Cancer Treated With SART1 Peptide-Pulsed Dendritic Cell Vaccine. Int J Oncol (2015) 46(4):1699-709. doi: $10.3892 /$ ijo.2015.2846

181. Dai S, Wei D, Wu Z, Zhou X, Wei X, Huang H, et al. Phase I Clinical Trial of Autologous Ascites-Derived Exosomes Combined With GM-CSF for Colorectal Cancer. Mol Ther (2008) 16(4):782-90. doi: 10.1038/mt.2008.1

182. Campos-da-Paz M, Dorea JG, Galdino AS, Lacava ZGM. De Fatima Menezes Almeida Santos M. Carcinoembryonic Antigen (CEA) and Hepatic Metastasis in Colorectal Cancer: Update on Biomarker for Clinical and Biotechnological Approaches. Recent Pat Biotechnol (2018) 12(4):269-79. doi: 10.2174/1872208312666180731104244

183. Pocsfalvi G, Mammadova R, Ramos Juarez AP, Bokka R, Trepiccione F, Capasso G. COVID-19 and Extracellular Vesicles: An Intriguing Interplay. Kidney Blood Press Res (2020) 45(5):661-70. doi: 10.1159/000511402

184. Fang X, Zheng P, Tang J, Liu Y. CD24: From A to Z. Cell Mol Immunol (2010) 7(2):100-3. doi: $10.1038 / \mathrm{cmi} .2009 .119$

185. Bai X-F, Liu J-Q, Liu X, Guo Y, Cox K, Wen J, et al. The Heat-Stable Antigen Determines Pathogenicity of Self-Reactive $\mathrm{T}$ Cells in Experimental Autoimmune Encephalomyelitis. J Clin Invest (2000) 105(9):1227-32. doi: $10.1172 /$ jci9012

186. Zheng C, Yin S, Yang Y, Yu Y, Xie X. CD24 Aggravates Acute Liver Injury in Autoimmune Hepatitis by Promoting IFN- $\gamma$ Production by CD $4+$ T Cells. Cell Mol Immunol (2017) 15(3):260-71. doi: 10.1038/cmi.2016.57

187. Akbari A, Rezaie J. Potential Therapeutic Application of Mesenchymal Stem Cell-Derived Exosomes in SARS-CoV-2 Pneumonia. Stem Cell Res Ther (2020) 11(1):356. doi: 10.1186/s13287-020-01866-6

188. Borger V, Weiss DJ, Anderson JD, Borras FE, Bussolati B, Carter DRF, et al. International Society for Extracellular Vesicles and International Society for 
Cell and Gene Therapy Statement on Extracellular Vesicles From Mesenchymal Stromal Cells and Other Cells: Considerations for Potential Therapeutic Agents to Suppress Coronavirus Disease-19. Cytotherapy (2020) 22(9):482-5. doi: 10.1016/j.jcyt.2020.05.002

189. Daassi D, Mahoney KM, Freeman GJ. The Importance of Exosomal PDL1 In Tumour Immune Evasion. Nat Rev Immunol (2020) 20(4):209-15. doi: 10.1038/s41577-019-0264-y

190. Syn NL, Wang L, Chow EK-H, Lim CT, Goh B-C. Exosomes in Cancer Nanomedicine and Immunotherapy: Prospects and Challenges. Trends Biotechnol (2017) 35(7):665-76. doi: 10.1016/j.tibtech.2017.03.004
Conflict of Interest: The authors declare that the research was conducted in the absence of any commercial or financial relationships that could be construed as a potential conflict of interest.

Copyright $\odot 2021$ Santos and Almeida. This is an open-access article distributed under the terms of the Creative Commons Attribution License (CC BY). The use, distribution or reproduction in other forums is permitted, provided the original author(s) and the copyright owner(s) are credited and that the original publication in this journal is cited, in accordance with accepted academic practice. No use, distribution or reproduction is permitted which does not comply with these terms. 